\title{
Developmental Objectives for Advanced Reactor Fuels
}

Nuclear Technology

Research and Development

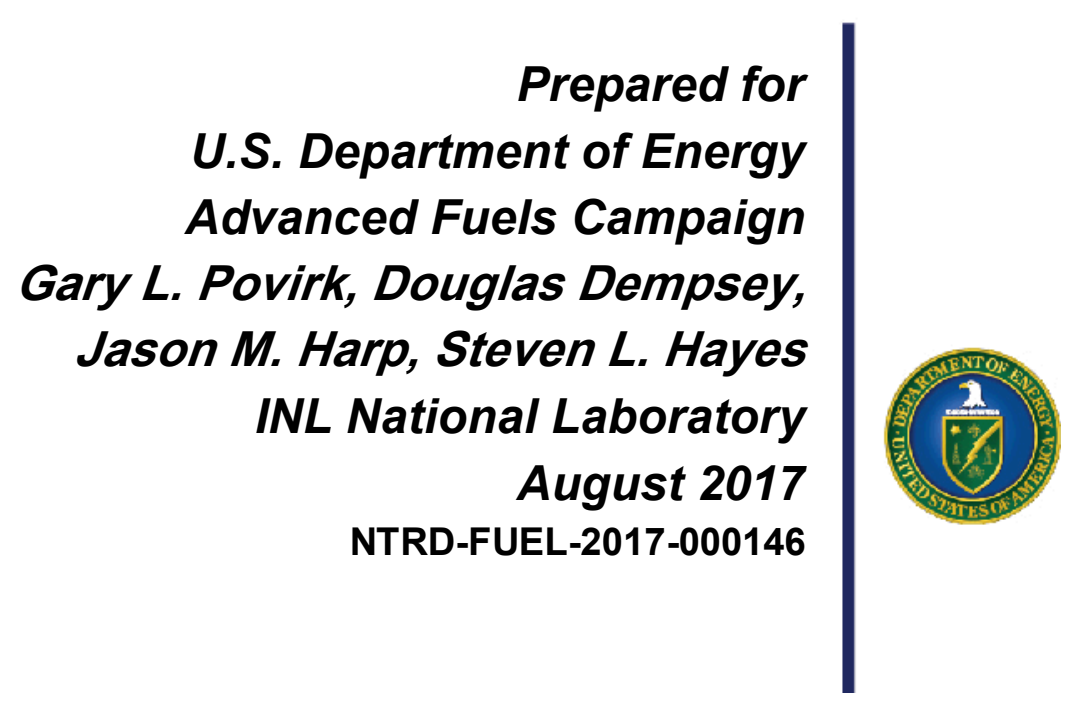




\section{DISCLAIMER}

This information was prepared as an account of work sponsored by an agency of the U.S. Government. Neither the U.S. Government nor any agency thereof, nor any of their employees, makes any warranty, expressed or implied, or assumes any legal liability or responsibility for the accuracy, completeness, or usefulness, of any information, apparatus, product, or process disclosed, or represents that its use would not infringe privately owned rights. References herein to any specific commercial product, process, or service by trade name, trade mark, manufacturer, or otherwise, does not necessarily constitute or imply its endorsement, recommendation, or favoring by the U.S. Government or any agency thereof. The views and opinions of authors expressed herein do not necessarily state or reflect those of the U.S. Government or any agency thereof. 


\section{SUMMARY}

This report summarizes the rationale for the activities needed to support the development of advanced metallic fast reactor fuel systems. To achieve this goal, the recommended approach is to continue programs in irradiation testing, postirradiation examinations, and fuel element fabrication, but also increase the emphasis placed on mechanistic fuel system modeling, literature reviews, validation of models against historic fuel performance data, and evaluation of the impact of prospective fuel designs on reactor plant performance. In this manner, once an irradiation test program is designed and initiated, there is not only an improved likelihood that the fuel system will behave as expected but there is also a better chance, if the testing is successful, that the fuel design will result in substantial improvements to reactor plant economics and/or safety.

The focus of the fuel development effort is complicated by the fact that there is not a well-defined reactor plant design to support. Given this situation, the approach will be to explore technically relevant fuel designs but also to develop an improved understanding of fuel performance fundamentals so that specific fuel designs for a given application can be developed with reduced time and cost.

Two broad classes of fuel designs will be pursued: (1) once-through fuel systems; and (2) fuels for enhanced actinide utilization that require recycling. For a once-through design, a major focus will be on the elimination of bond sodium, which in turn will allow for the direct disposal of the fuel in a geological repository. Fuel designs for enhanced actinide utilization, however, have significantly different constraints and objectives than a once-through fuel system. The focus here will be on fuel shapes that can be fabricated within a hot cell and fuel element designs that can achieve high energy and power density. Based on preliminary analyses, notional test matrices are proposed for both once-through and recycled fuel system designs. Further work is required, however, to better define these designs and to develop the associated experimental programs. 
INTENTIONALLY BLANK 


\section{CONTENTS}

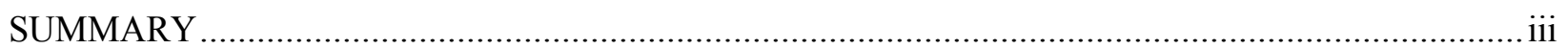

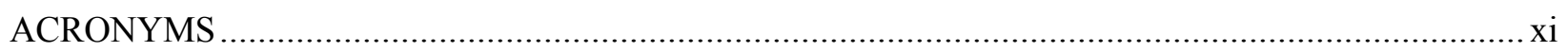

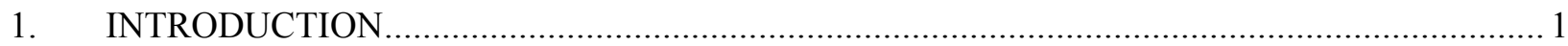

2. OVERVIEW OF METALLIC FUEL BEHAVIOR …............................................................. 3

3. DESIGN LIMITS AND PERFORMANCE METRICS ............................................................ 4

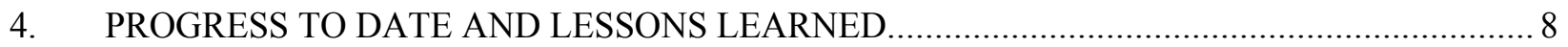

4.1 Difficulties with Testing in the ATR ....................................................................... 8

4.2 Solid, Sodium Bonded Fuel with Reduced Smear Density ............................................. 13

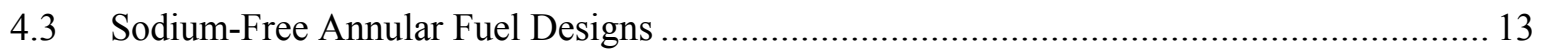

4.4 U-10Mo Alloy Fuel .............................................................................................. 13

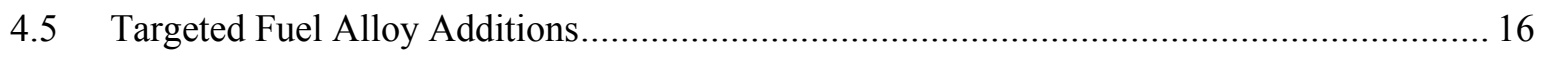

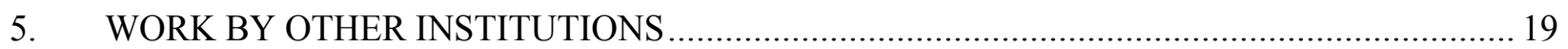

6. EFFECT OF BOND SODIUM ON FUEL TEMPERATURES …............................................. 20

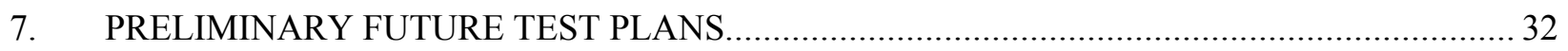

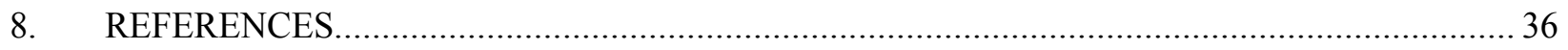

\section{FIGURES}

Figure 1. A schematic showing the components of a fuel system development program. A successful program will integrate all of the activities to produce a compelling design at minimum cost, both in terms of financial resources but also with respect to time......

Figure 2. Fuel performance limits and their potential impact on core design is an essential part of a fuel system design and development program. (a) a schematic showing how allowable temperatures, an allowable amount of cladding deformation, and an allowable amount of fuel/cladding chemical interaction might limit fuel pin power and burnup; and (b) a schematic of a notational design limit that might result. ....

Figure 3. (a) The use of a unit cell model for a single pin will likely be useful for comparing fuel element designs that use different pin and wire wrap diameters; (b) for example, power and burnup limits for a given fuel system design can be used in conjunction with an associated unit cell model to provide rough estimates of fuel assembly power and energy densities, which in turn allow different fuel systems to be compared on the same basis. Other simple metrics that can be obtained from a unit cell model include volume fractions of structural materials, void space, coolant, and fissile and fertile materials. 
Figure 4. (a) For a given technology, the capability of the fuel system can be "spent" in different ways, depending on the application. For example, reducing pin diameter while keeping wire diameter and smear density fixed will increase power density at the expense of energy density. Conversely, increasing pin diameter while keeping wire diameter fixed will increase energy density at the expense of power density; (b) More advanced technologies will expand the overall design space.

Figure 5. Design of the rodlet, capsule, and basket used to test fast reactor fuels in the ATR. Note that there is a 0.002 " gap between the outside diameter of the rodlet and the inside diameter of the capsule. This gap is filled with helium and is used to be bring cladding surface temperatures up to levels that are prototypical for a sodium-cooled fast reactor (roughly $300-500^{\circ} \mathrm{C}$ ). Given the small dimensions of the gap, the current approach requires very tight tolerances with regard to the pin outside diameter, the capsule inside diameter, and placing the rodlet within the capsule in a concentric manner. Moreover, the small gas-filled gap make fuel pin temperatures very sensitive to ATR power levels.

Figure 6. Design of the rodlet, capsule, and basket used to test fast reactor fuels in the ATR. Note that there is a 0.002 " gap between the outside diameter of the rodlet and the inside diameter of the capsule. This gap is filled with helium and is used to be bring cladding surface temperatures up to levels that are prototypical for a sodium-cooled fast reactor (roughly $300-500^{\circ} \mathrm{C}$ ). Given the small dimensions of the gap, the current approach requires very tight tolerances with regard to the pin outside diameter, the capsule inside diameter, and placing the rodlet within the capsule in a concentric manner. Moreover, the small gas-filled gap make fuel pin temperatures very sensitive to ATR power levels.

Figure 7. (a) Drawing of the current capsule design for testing metallic fast reactor fuels in the ATR; (b) Schematic of the instrumented capsule for the TMIST program; and (c) A potential instrumented design for testing metallic fuels.

Figure 8. Neutron radiographs of low smear density (55 percent) pins taken to burnups of about 2-4 atom percent. ${ }^{12}$ Note that the sodium-bonded, solid fuel designs exhibited liftoff, extensive axial deformation, and had unusual distributions of fuel within the cladding; in contrast, the annular design shows little evidence of axial extension of the fuel and the distribution of fuel within the pin appears to be relatively uniform. The features associated with the solid fuel designs will result in substantial increases in uncertainties from the reactor physics point of view, and the uneven distribution of fuel raise concerns about fuel slumping that will be difficult to address. For these reasons, the pursuit of sodium-bonded solid fuel designs with low smear density (e.g., less than 75 percent) will be discontinued.

Figure 9. Micrographs of a rodlet with annular U-10Zr, a smear density of 55 percent, and without the use of sodium bond. ${ }^{12}$ Note the region of high porosity (and therefore degraded thermal conductivity) along the fuel/cladding interface and the area that shows accelerated fuel/cladding chemical interaction. Overall, however, performance of the low smear density, annular designs with U-10Zr appears to be satisfactory. Continued investigations and testing of annular designs is recommended along with evaluating methods to mitigate concerns regarding reduced thermal conductivity and enhanced fuel/cladding chemical interactions. 
Figure 10. Micrographs rodlets with (a) U-10Zr; and (b) U-10Mo, each with an initially annular configuration, a smear density of 55 percent, and free from the use of sodium bond. ${ }^{12}$ Compared with the U-10Zr alloy, the fuel pin with U-10Mo shows large amounts of fuel/cladding chemical interaction and possibly centerline melting of the fuel. The U$10 \mathrm{Zr}$ pin may have avoided melting because the migration of zirconium towards the pin center (and the corresponding migration of uranium away from the pin center) has the effect of increasing the solidus temperature near the center of the pin and moving power towards the fuel/cladding interface. Based on these results, the testing of U-Mo alloys for fast reactor applications will be continued only after evaluating designs that employ liners.

Figure 11. A plot of the enthalpy of formation for various elements reacting to form indiumbearing compounds as a function of indium concentration. ${ }^{1}$ The plot shows that although the formation of lanthanide compounds with a potential getter (indium, in this case) is energetically favored, the formation of zirconium compounds with the getter is almost as favorable. Given that zirconium is the most common alloying element for metallic fast reactor fuels, a concern is that the gettering agent might react with zirconium and not the lathanides.

Figure 12. (a) A micrograph taken from Reference [4] that shows a number of different kinds of precipitates that have formed in a U-15Zr-3.86Pd-4.3Ln alloy, where $\mathrm{Ln}=53 \mathrm{Nd}-25 \mathrm{Ce}-$ 16Pr-6La (all percentages are in wt\%). (b) A table provided from Reference 4 that shows the compositions of the various precipitates (in atom fractions) as determined by standardless energy dispersive X-ray analysis. The red box highlights precipitates that contain lanthanides while the blue box indicates compounds that are free of lanthanides. Note that the majority of the palladium is in the lanthanide-bearing precipitates and the excess palladium is found in the compounds without lanthanides. The results indicate that the palladium does tie up the lanthanides preferentially to zirconium, which in turn suggests that palladium should perform well as a lanthanide getter.

Figure 13. Micrographs of annular, 55 percent smear density fuel pins with either (a) U-10Zr; or (b) U-4Pd-10Zr. ${ }^{12}$ Ironically, the pin with the palladium appears to have more fuel/cladding chemical interaction than the standard U-10Zr alloy. Preliminary work ${ }^{14}$ indicates that most of the zirconium and palladium migrated to the center of the pin. There was, therefore, little palladium left to getter fission products near the fuel/cladding interface. The palladium appears to have reacted and migrated with the zirconium prior to the availability of lanthanide fission products. Once compounds of zirconium and palladium formed, there maybe be an insufficient thermodynamic driving force for reactions between the palladium and the lanthanides.

Figure 14. Shapes of fuel columns being explored by RIAR. ${ }^{15}$

Figure 15. Micrographs from Russian work ${ }^{15}$ on metallic fuel that uses helium bonding, slots along the length of the fuel column to accommodate fission products, fuel compositions of either pure uranium or uranium-plutonium alloys, and a liner between the fuel and the cladding to reduce fuel/cladding chemical interactions. (a) Near the top of the core the burnup was apparently quite low so the original fuel geometry is evident; (b) lower in the core, ovalization of the fuel rod was observed. The Russians have an extensive effort in this area, having tested about 100 full-sized fuel assemblies more than 3000 fuel pins with metallic fuel. ${ }^{16}$. 
Figure 16. Measurements of yield strength as a function of temperature for an irradiated stainless steel cladding and for fuel alloys of various compositions. ${ }^{17}$ Although such data do not characterize the in-reactor response of these materials, they do provide some guidance as to the strength of the fuel relative to the cladding and the effects of alloying additions on fuel mechanical strength

Figure 17. One slide taken from a presentation prepared by representatives of the Bhabha Atomic Research Centre (BARC) in Mumbai, India. ${ }^{18}$ The Indians appear to be pursuing technology based on both American and Russian experience.

Figure 18. Figures taken from Reference 19 that show metallography of sodium infiltration into a metal fuel pin and the corresponding porosity distribution in the fuel (dark areas in the micrographs are indicative of high concentrations of sodium). Very roughly, the results indicate sodium infiltration where porosity is greater than about 30-40 percent.

Figure 19. Estimates of sodium infiltration taken from Reference 20. The results indicate that for $75 \%$ smear density pins, about 20 to 40 percent of the porosity in the fuel will be filled with sodium. Based on the metallography and porosity estimates in Reference 20, more sodium infiltration can be expected for lower smear density pins.

Figure 20. Estimates of thermal conductivity for different constituents that potentially comprise a metallic fuel pin [21,22]. Of all the constituents in a metallic fuel system, sodium has the highest thermal conductivity in the temperature range of interest. Also note that although the addition of zirconium to metallic fuel increases its solidus temperature, zirconium also reduces the thermal conductivity of uranium and uranium-plutonium alloys.

Figure 21. Estimates of the effective thermal conductivity for uranium metal as a function of porosity and the fraction of porosity that has been infiltrated with sodium. Although the thermal conductivity model uses the (overly) simplistic rule of mixtures, a key trend can be nonetheless identified, namely that the effect of sodium on effective thermal conductivity is more pronounced at high values of fuel porosity and high values of sodium infiltration. Given that more sodium infiltration can be expected in fuels with high porosity, the results indicate that the advantage regarding the use of sodium bond is much more pronounced for high porosity (e.g., low smear density) fuel system designs

Figure 22. Estimates of solidi temperatures for uranium-zirconium ${ }^{26}$ and uranium-plutonium alloys. ${ }^{27}$

Figure 23. Estimates of solidus temperatures for U-Pu-Zr alloys from Reference 25

Figure 24. Fuel systems designed to achieved high burnup (low smear density, liner, zirconium removed from the fuel alloy, sodium bond, (see Table 2) have about the same margin to centerline melting as annular fuel designs with $75 \%$ smear density, no sodium bond, and the use of standard metal fuel alloys with $10 \mathrm{wt} \% \mathrm{Zr}$. For these cases, the addition of the bond sodium in the high burnup designs is enough to offset reduced smear density and the low melting points of the uranium and uranium-plutonium alloys. A key assumption in these estimates, however, is that the low smear density in the high burnup designs will enable 50 percent of the porosity to be filled with sodium. See also Table 2 for assumptions made in the analyses. 
Figure 25. The impact of sodium bond on power-to-centerline melting is greater in the low smear density cases because the effect of sodium on thermal conductivity is greater with higher porosity and higher amounts of infiltration. The impact on power is greater for $\mathrm{U}-20 \mathrm{Pu}$ than for pure uranium (on a percentage basis) because U-20Pu has lower thermal conductivity than uranium so the addition of sodium has a greater impact on the net thermal conductivity of U-20Pu.

Figure 26. Example fuel designs for (a) a once-through fuel system; and (b) a design when fuel recycling is anticipated.

Figure 27. Examples of slotted fuel designs with about 60 percent smear density.

Figure 28. (a) Schematic of directional solidification of a gas-saturated melt and the elongated porosity that can result; and (b) Metallography of porosity in copper fabricated under different conditions (Figures were taken from Reference 24). An alternative to both annular and slotted fuel designs would be porous fuel.

\section{TABLES}

Table 1. Estimates of Solidus or Melting Point for a Variety of Potential Metal Fuels.

Table 2. Examples of Different Fuel Element Designs to Illustrate the Effects of Bond Sodium.

Table 3. Increase in Power-to-Melt Associated with the Presence of Bond Sodium. 31

Table 4. Test Matrix for Once-Through Fuel Element Designs. 35

Table 5. Test Matrix for Recycling Fuel Element Designs. 35 
INTENTIONALLY BLANK 


\section{ACRONYMS}

AFC Advanced Fuels Campaign

ATR Advanced Test Reactor

BARC Bhabha Atomic Research Centre (India)

DOE Department of Energy

EBR Experimental Breeder Reactor

FCCI Fuel/Cladding Chemical Interaction

INL Idaho National Laboratory

MFC Materials \& Fuels Complex

RIAR Research Institute of Atomic Reactors (Russia)

SD Smear Density

TMIST Tritium Producing Burnable Absorbent Rod (TPBAR) Materials Irradiation Separate Effects Test (TMIST)

VTR Versatile Test Reactor 
INTENTIONALLY BLANK 


\section{DEVELOPMENTAL OBJECTIVES FOR ADVANCED REACTOR FUELS}

\section{INTRODUCTION}

Metallic fuels have a history of use that spans the entire nuclear age, from the early plutonium production reactors (1940s) and the first liquid metal fast breeder reactors (1950s) to the most advanced reactor designs of today. Initially, metallic fuels were employed for their ease of fabrication and high heavy metal density. During subsequent decades, metallic fuel technology matured significantly, leading to the realization of major benefits in fuel reliability and burnup, proliferation-resistant recycling, remote fabrication, and passive reactor safety. These characteristics make metallic fuels particularly well-suited for use in sodium-cooled fast spectrum reactors.

Although sodium-cooled reactors have substantial benefits over current light water reactor technology in terms of safety and actinide utilization, worldwide use of sodium-cooled reactors remains limited. Reasons for the lack of commercial success are complex, but the primary issue involves cost, both for construction and operation of reactor plants as well as the time and cost required to advance key technologies. Given the time and expense associated with irradiation testing and the lack of a fast spectrum test reactor in the United States, fuels and materials technologies are among the most difficult to develop and advance.

For any technology, the pace of development is determined in part by the time and expense required to explore alternatives to the current state of the art. For example, the capabilities of advanced modeling and simulation are growing exponentially in large part because the costs of experimentation are so low (e.g., a programmer can often try out a new idea in a matter of minutes). For nuclear fuels and materials, the time and cost of iterating on alternatives is extremely high, which in turn helps to explain why nuclear reactor development can be excruciatingly slow. The pace of development, however, can be accelerated in two distinct ways: (1) improvements in the productivity of our irradiation testing and postirradiation examinations infrastructure; (2) the use of a variety of alternatives to radiological work, including mechanistic fuel modeling, extensive literature reviews, increased reliance on out-of-reactor testing, and evaluation of the impact of fuel system developments on reactor plant performance.

Viewed in this context, a fuel development program consists not only of test pin fabrication, irradiation testing, and postirradiation examinations, but also on development and use of physically-based models, out-of-reactor testing, validation of models against historic fuel performance data, and literature reviews (see Figure 1). Of course, elements of these efforts are already in place, but increased emphasis on these activities are expected to speed the fuel development effort. Quite simply, the approach calls for obtaining as much knowledge and understanding as possible using whatever means necessary while minimizing the amount of radiological work that is required. In this manner, once an irradiation test program is designed and initiated, there is not only an improved likelihood that the fuel system will behave as expected but there is also a better chance, if the testing is successful, that the fuel design will result in substantial improvements to reactor plant economics and/or safety.

The focus of the fuel development effort is complicated by the fact that there is not an associated, well-defined reactor plant activity to inform fuel research and development directions and drive down-selections. Potential customers to the Advanced Fuels Campaign (AFC) include the Versatile Test Reactor (VTR) and the burner reactor concepts being pursued by the Department of Energy, breed-and-burn reactor designs (TerraPower), and fuel systems for more conventional sodium-cooled fast reactors (GE-Hitachi, Advanced Reactor Concepts, OKLO). Given this situation, the approach will be to explore technically relevant fuel designs but also to develop an improved understanding of fuel performance fundamentals so that specific fuel designs for a given application can be developed with reduced time and 


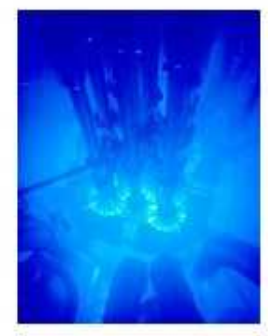

Irradiation testing

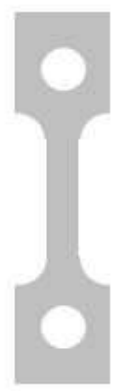

Out-of-reactor testing
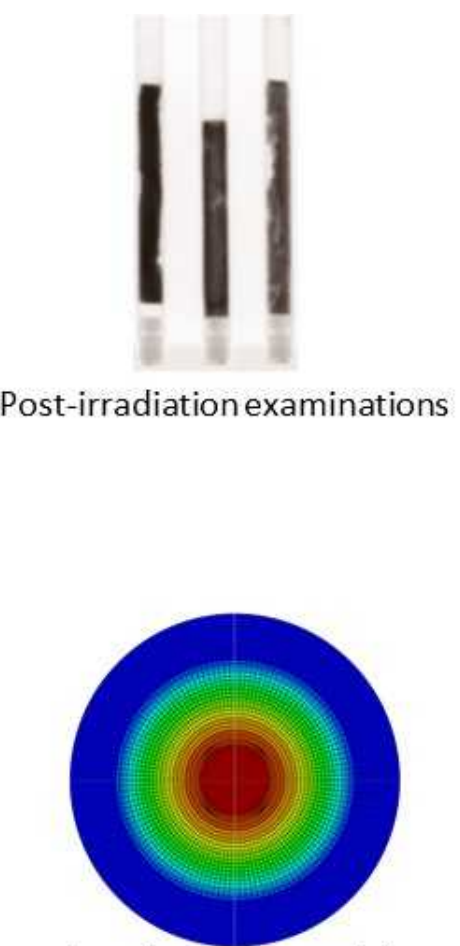

Fuel performance modeling

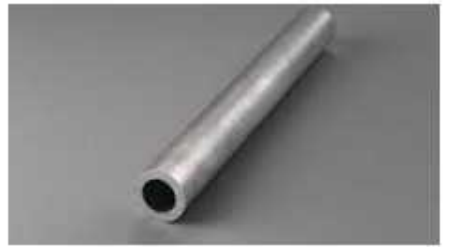

Fabrication development

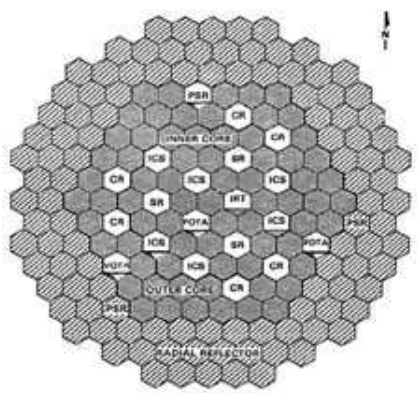

Core design

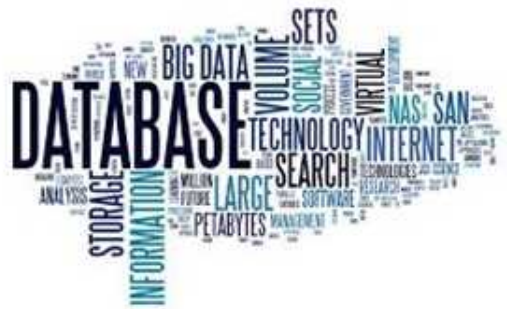

Fuel performance data \& literature reviews

Figure 1. A schematic showing the components of a fuel system development program. A successful program will integrate all of the activities to produce a compelling design at minimum cost, both in terms of financial resources but also with respect to time.

cost. To make matters more specific, two broad classes of fuel designs will be pursued: (1) once-through fuel systems; and (2) fuels for enhanced actinide utilization that would require recycling. For a once-through design, a major focus will be on the elimination of bond sodium, which should facilitate the direct disposal of the fuel in a geological repository. This work will build upon existing efforts to fabricate and characterize the behavior of sodium-free annular fuel, but it will also emphasize fuel alloys that are likely to be employed for the VTR. Fuel designs for enhanced actinide utilization, however, have significantly different constraints and objectives than a once-through fuel system. The focus here will be on fuel shapes that can be fabricated within a hot cell and fuel element designs that can achieve high energy and power density. 
Before describing future test plans in detail, however, a variety of topics will be surveyed to provide a basis for the decisions made regarding the direction of the experimental program. Factors that affect the performance of metallic fuel systems are reviewed and the behaviors that limit pin performance are described, which then lead into a discussion of notional design limits for metallic fuel. The concept of a unit cell model consisting of a single pin and the surrounding coolant channel is introduced; combined with fuel performance limits, these simple models can be employed to estimate approximate core performance metrics such as power density, energy density, volume fractions of fissile material, etc. that in turn can be helpful in evaluating the merits of a given fuel design. The results from recent AFC tests are reviewed and conclusions are drawn, both with respect to difficulties associated with testing fast reactor fuel in the Idaho National Laboratory (INL) Advanced Test reactor (ATR) but also in regard to which of the technologies that have been investigated to date warrant further consideration and continued development. In addition to recently acquired data through the Advanced Fuels Campaign, results from other metallic fuel development programs are discussed, with particular emphasis on the extensive effort of the Russian program. Finally, simple analyses that explore the effects of bond sodium on effective fuel thermal conductivity and fuel temperatures are presented that show the relative benefits of sodium depending on a particular fuel system design.

The report culminates in a discussion of fuel pin designs and test plans for both once-through fuel designs and fuel systems targeting enhanced actinide utilization. These designs and plans are based in part on placing a high priority on the development of a second generation, sodium-free fuel system for the VTR. In addition, however, preliminary designs for fuel systems for enhanced actinide utilization are presented that attempt to account for limitations in hot cell fabrication and the need for increase burnup capability while maintaining high heavy metal loadings. Given the approximate nature of these studies, details of the plans are expected to evolve with time, but the guiding principles used to development the experiments are expected to endure.

\section{OVERVIEW OF METALLIC FUEL BEHAVIOR}

From a materials perspective, metallic fuel systems exhibit a variety of behaviors that potentially can limit fuel element burnup, power, and lifetime:

(a) Excessive distortion: Deformation of the fuel pin can be caused either by the accumulation of fission products (internal pressurization) or by neutron-induced swelling of the cladding. Excessive distortions can lead to duct dilation or flow maldistribution within the assembly.

(b) Creep Rupture: Creep rupture of the cladding, caused by internal pressurization of the fuel pin and excessive thermal creep in the cladding. Creep rupture is typically a concern at high axial elevations during accident conditions.

(c) Eutectic Formation: Melting near the fuel/cladding interface because of low melting point eutectics that can form from chemical constituents in the cladding and fuel, typically iron and uranium or plutonium. Note that this mechanism requires inter-diffusion between the cladding and fuel so that the kinetics of this process are also important.

(d) Centerline Melting: Melting of the fuel near its center, which in turn raises concerns regarding fuel slumping.

(e) Constituent Migration: A phenomenon that is related to the development of different phases within the fuel due to radial and axial gradients in temperature. For U-10Zr and U-20Pu-10Zr alloys, zirconium tends to migrate into the center of the fuel, which provides a benefit by raising the solidus temperature. A potential concern, however, is that having radial variations in the crystal structure of the alloy may assist in the transport of lanthanides to the fuel/cladding interface. ${ }^{1}$

(f) Fuel/Cladding Chemical Interaction (FCCI): Lanthanide fission products are known to attack the cladding and form brittle phases that degrade the structural integrity of the fuel element. FCCI is a 
key phenomenon that limits the lifetime of metallic fuel systems and it's a strong function of the initial fuel composition and the particular alloy used for the cladding.

A central focus for the fuel development effort is to both explore ways to mitigate these limiting behaviors and to characterize these phenomena through irradiation testing and postirradiation examinations. For example, it has been long established ${ }^{2,3}$ that reduced smear density provides more volume to accommodate the build-up of fission products, and that the interconnection of porosity and the use of a plenum can reduce fission gas pressure even further. A reduction in gas pressure, in turn, reduces the driving force for cladding deformation that can fuel limit burnup. Similarly, the use of either fission product getters or diffusion barriers ${ }^{4,5}$ have the potential to either reduce or eliminate concerns regarding fuel/cladding chemical interactions. To ensure that irradiation testing of a new design feature is worthwhile, however, its impact to core performance must be evaluated, even if in an approximate manner.

\section{DESIGN LIMITS AND PERFORMANCE METRICS}

Developing an understanding of limiting phenomena in a fuel design and the impact that these behaviors have on reactor performance is an essential part of fuel system design and development. The objective of the following discussion is to describe how limiting phenomena are accounted for when creating fuel performance limits that would be used by a core designer and how these limits in turn can be used to estimate simple metrics for core performance. To simplify matters, the discussion will consider only steady-state limits at a given axial location (e.g., at a given cladding surface temperature). Furthermore, the plots of various limiting phenomena are notational in nature and are not intended to describe actual steady-state limits for a metallic fuel pin. Rather, the intent is to illustrate how fuel design limits might be constructed, and how fuel element designs with different dimensions can be compared on an equivalent basis.

Figure 2a illustrates how limiting phenomena such as allowable cladding strain, centerline melting of the fuel, the formation of low-melting point eutectics at the fuel/cladding interface, and excessive degradation of the cladding by fuel/cladding chemical interaction might vary as a function fuel element power and fission density. Accounting for the design margins that will be applied, the limiting envelop of these different phenomena can then be used to define a region within power and burnup space where the fuel pin can operate reliably (see Figure 2b).

What is most relevant from the perspective of reactor performance, however, is not allowable pin power or pin burnup, but fuel assembly power and energy density (in this case, what is meant by energy density is the energy extracted from the fuel assembly relative to its volume before the assembly needs replacement). To estimate power and energy density, a simple unit cell model can be constructed that consists of a single fuel pin surrounded by the sodium coolant (see

Figure 3a). Given the dimension of the unit cell and the design limits for power and burnup (which can be in whatever units that are convenient), estimates for fuel assembly power and energy density can be found by calculating the allowable power and energy per unit volume of the cell (

Figure 3b). These estimates are particularly useful when comparing fuel element designs that employ different dimensions for cladding diameter, cladding thickness, or wire wrap diameter.

Unit cell models can also be used to illustrate how pin dimensions and spacing can be varied to accommodate the needs of a particular design. As an example,

Figure 4a shows that reducing pin diameter while keeping wire diameter and smear density fixed will increase power density at the expense of energy density (assuming that fuel centerline temperature is limiting power). Conversely, increasing pin diameter while keeping wire diameter fixed will increase energy density at the expense of power density. These simple examples show that for a given technology, 
the capability of the fuel system can be "spent" in different ways, depending on the application. Ideally, of course, the objective of the experimental program is to expand the design space so that both power and energy density can be increased (see

Figure 4b).

\section{Limiting Phenomena}

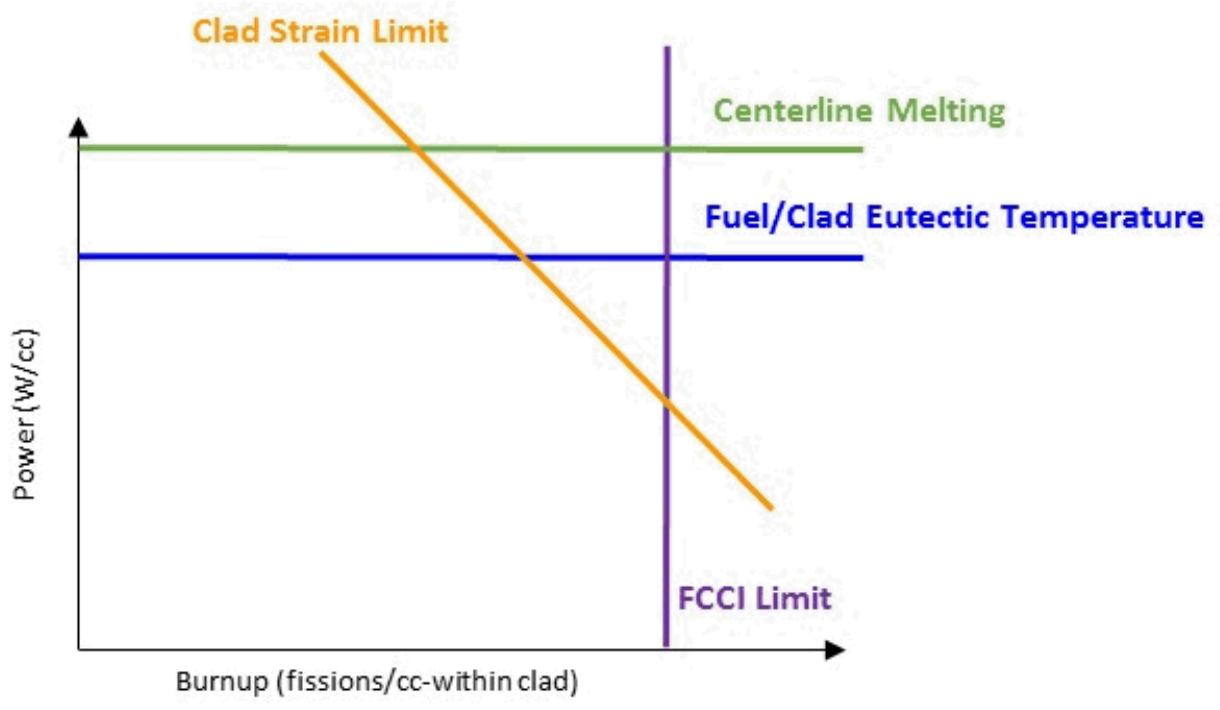

(a)

\section{Notational Design Limit}

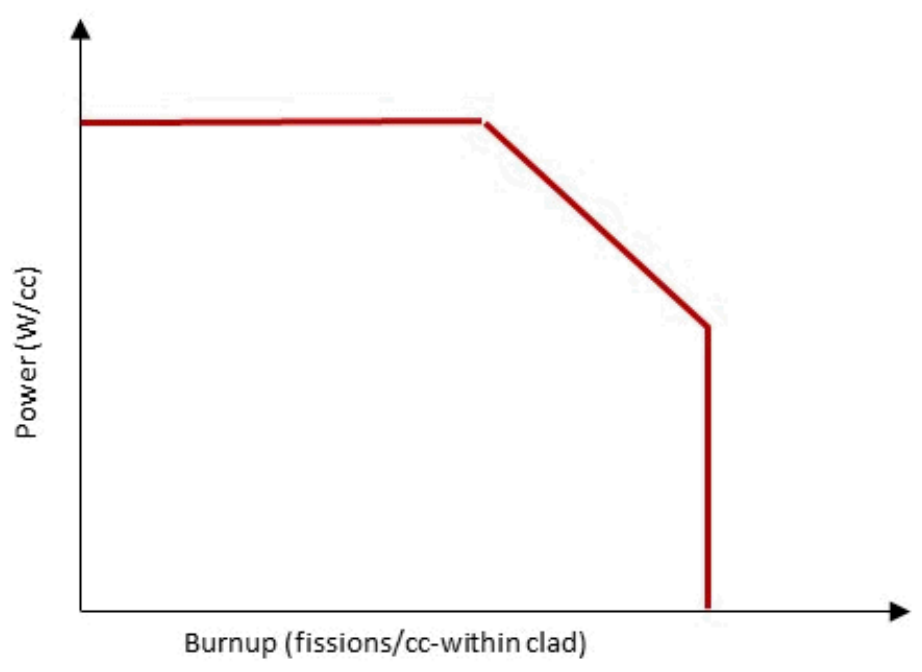

(b)

Figure 2. Fuel performance limits and their potential impact on core design is an essential part of a fuel system design and development program. (a) a schematic showing how allowable temperatures, an 
allowable amount of cladding deformation, and an allowable amount of fuel/cladding chemical interaction might limit fuel pin power and burnup; and (b) a schematic of a notational design limit that might result.

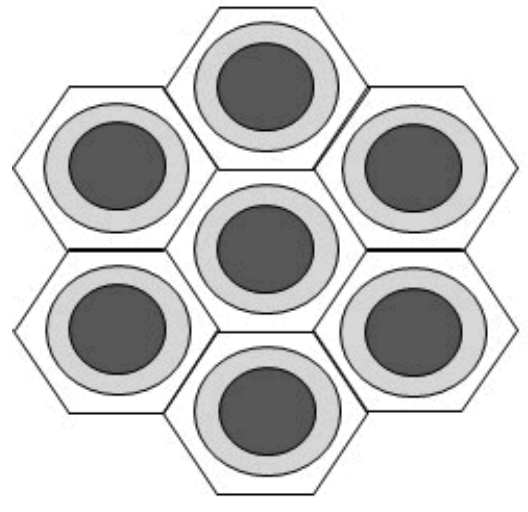

An array of fuel pins within an assembly (wire wrap not shown)

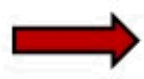

A single unit cell consisting of a fuel pin and associated coolant channel

(a)

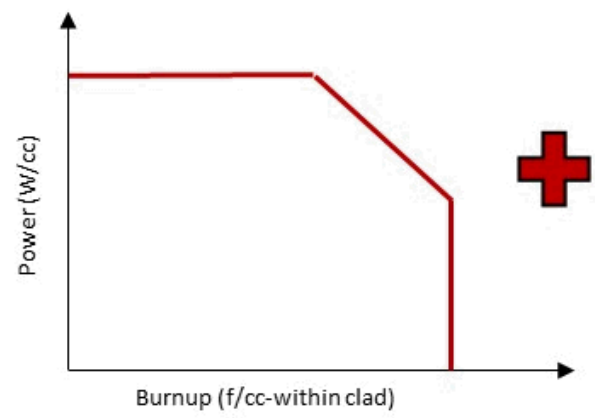

Burnup (f/cc-within clad)

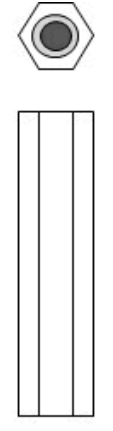

Unit cell
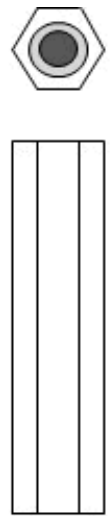

\section{a)}

\section{(b)}

Figure 3. (a) The use of a unit cell model for a single pin will likely be useful for comparing fuel element designs that use different pin and wire wrap diameters; (b) for example, power and burnup limits for a given fuel system design can be used in conjunction with an associated unit cell model to provide rough estimates of fuel assembly power and energy densities, which in turn allow different fuel systems to be compared on the same basis. Other simple metrics that can be obtained from a unit cell model include volume fractions of structural materials, void space, coolant, and fissile and fertile materials. 


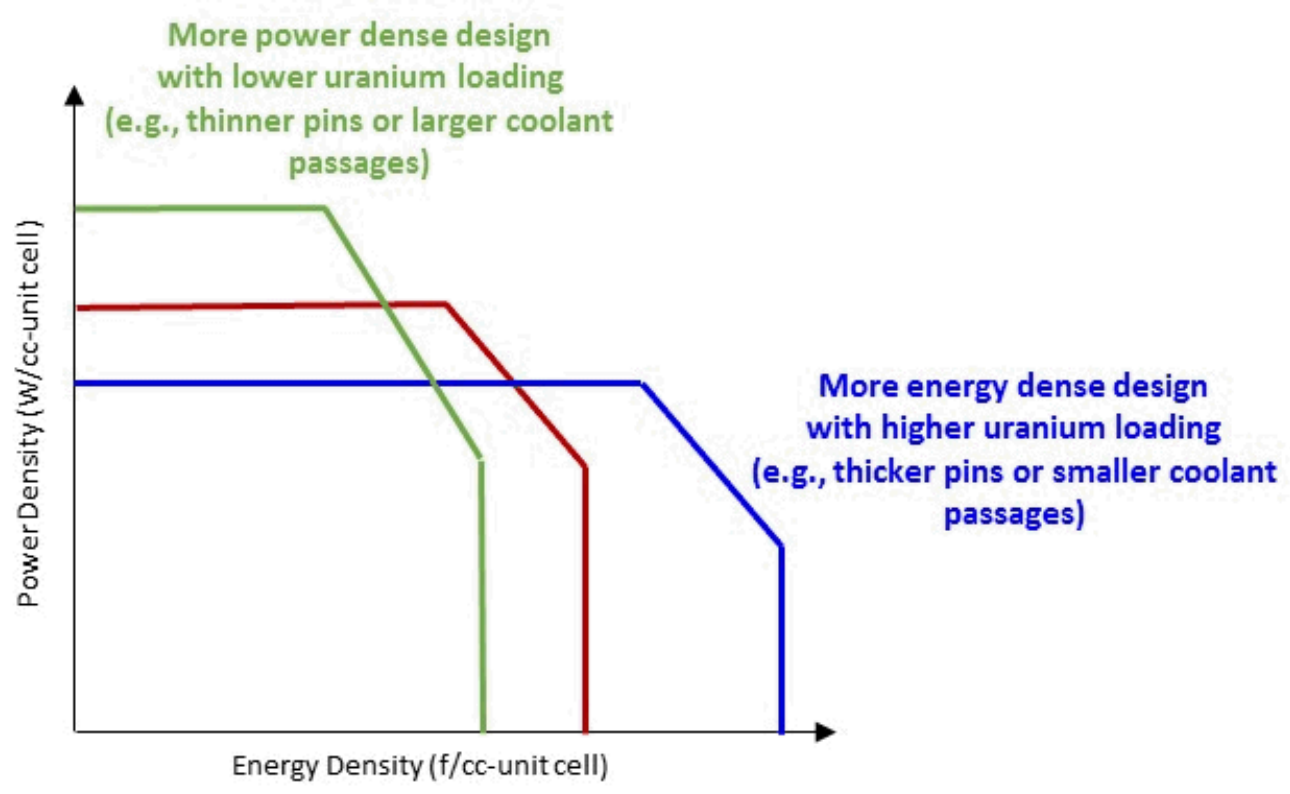

(a)

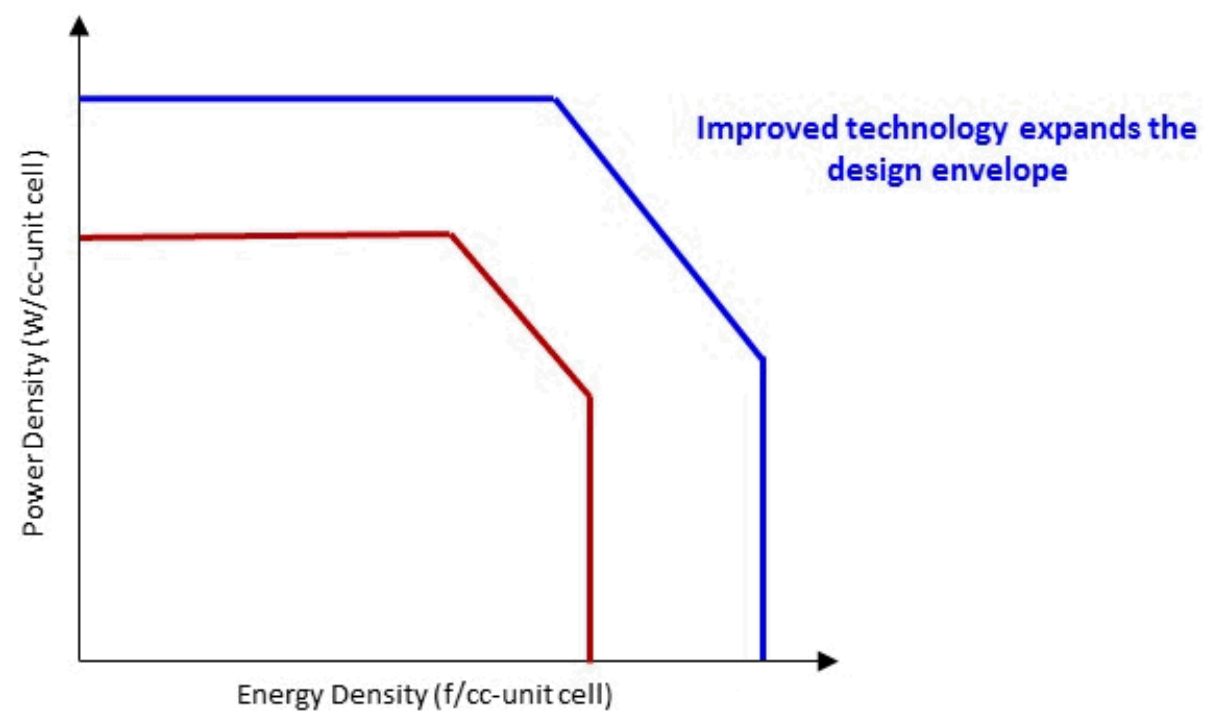

(b)

Figure 4. (a) For a given technology, the capability of the fuel system can be "spent" in different ways, depending on the application. For example, reducing pin diameter while keeping wire diameter and smear density fixed will increase power density at the expense of energy density. Conversely, increasing pin diameter while keeping wire diameter fixed will increase energy density at the expense of power density; (b) more advanced technologies will expand the overall design space. 
Power and energy density are not the only relevant metrics for core performance, however, and are only emphasized here as a means of illustrating how unit cell models can be used to evaluate the merits of a given fuel element design. Other simple metrics that can be obtained from a unit cell model include coolant flow area and volume fractions of structural materials, void space, coolant, and fissile and fertile materials. These metrics are, of course, not a substitute for a complete evaluation by a core design team, but they do provide guidance for determining fuel system design and development priorities.

\section{PROGRESS TO DATE AND LESSONS LEARNED}

The test data obtained in the AFC program over the past decade also provides key information that will be used to set direction for future experiments. Technologies that have been investigated to date include:

(a) Reduced fuel smear density: A further decrease in the fuel smear density to levels below 75 percent will allow for the accommodation of fission products to higher burnups without inducing unacceptable levels of fuel pin distortion. ${ }^{2,3}$

(b) Sodium-free annular fuel: The use of annular fuel that is either mechanically- or helium-bonded to the cladding provides a means to remove the sodium bond and presumably allow for the direct disposal of once-through metallic fuel into a geological repository. ${ }^{6,7}$

(c) U-10Mo fuel alloy: The uranium-molybdenum based alloy system results in a stabilization of the $\gamma$ (body-centered cubic) phase of uranium across a wide temperature range, which could eliminate fuel constituent redistribution and potentially reduce the migration of lanthanide fission products to the fuel/cladding interface. ${ }^{1}$ In addition, replacing zirconium with molybdenum increases both fuel thermal conductivity and fuel solidus temperature. The drawback to the U-Mo fuel alloy is an expected increase in fuel-cladding chemical interaction with stainless steel claddings, so realization of this design innovation may be predicated on finding an acceptable cladding coating or liner.

(d) Targeted fuel alloy additions: Lanthanide fission products migrate to the fuel-cladding interface, react with the steel cladding to form a brittle interaction product with a decreased melting point, and ultimately reduce the load-carrying capability of the cladding. Targeted, minor alloy additions that will chemically bind with the lanthanides and immobilize them in the fuel matrix, thus preventing their transport to the fuel-cladding interface, are under investigation. ${ }^{1,4}$

In the following, results from these investigations are reviewed and recommendations are made for how and whether pursuit of these technologies will continue. Before describing the results for the experiments, however, difficulties of testing fast reactor fuel in the ATR will be discussed.

\subsection{Difficulties with Testing in the ATR}

Figure 5 shows the design of the rodlet, capsule, and basket used to test fast reactor fuels in the ATR. Note that there is a 0.002 in. gap between the outside diameter of the rodlet and the inside diameter of the capsule. This gap is filled with pure helium and is used to be bring cladding surface temperatures up to levels that are prototypical for a sodium-cooled fast reactor (roughly $350-550^{\circ} \mathrm{C}$ ). Given the small dimensions of the gap, the current approach requires very tight tolerances with regard to the rodlet outside diameter, the capsule inside diameter, and placing the rodlet within the capsule in a concentric manner. Moreover, the small gas-filled gap make fuel pin temperatures very sensitive to off-nominal changes to power levels, which unfortunately are quite common in ATR operations.

The experience with the AFC-2A, AFC-2B, and AFC-2E experiments illustrate these challenges. In these tests, rodlet breaches initially occurred because of a combination of large fabrication tolerances associated with the inner capsule diameter, higher-than-expected reactor power levels, and the approximate nature of how the helium gas gap was modeled in the thermal analyses. These difficulties were compounded because the experiments were designed such that a single capsule contained six rodlets. Unfortunately, with this particular design, the failure of one pin introduces the fission gases xenon and krypton into the gas gap, which in turn results in a substantial reduction in gas gap thermal conductance. In this manner, 
the failure of a single rodlet resulted in an escalation of temperatures for all of the rodlets in the capsule and caused a cascade of additional rodlet failures. ${ }^{8}$

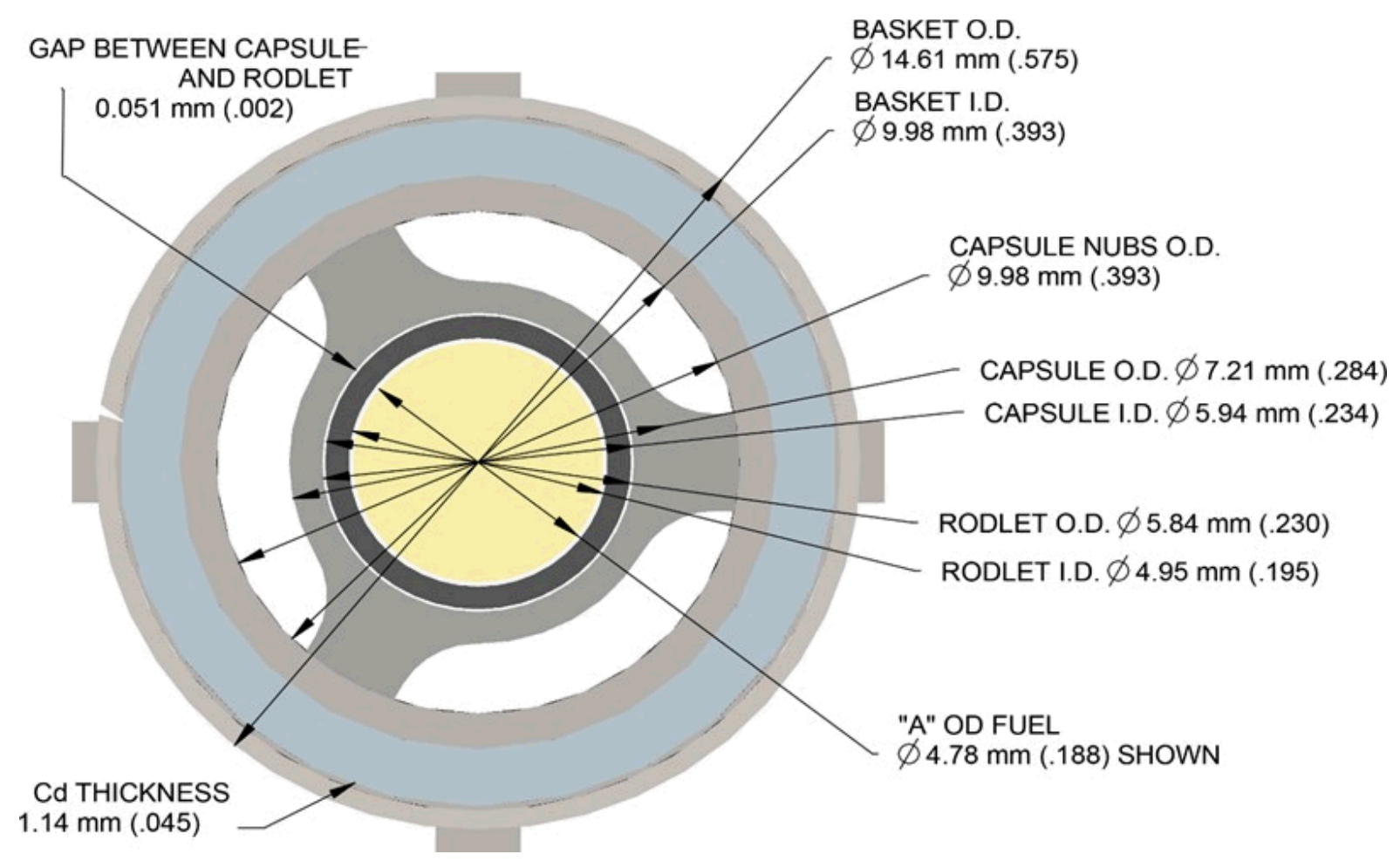

Figure 5. Design of the rodlet, capsule, and basket used to test fast reactor fuels in the ATR. Note that there is a 0.002" gap between the outside diameter of the rodlet and the inside diameter of the capsule. This gap is filled with helium and is used to be bring cladding surface temperatures up to levels that are prototypical for a sodium-cooled fast reactor (roughly $300-500^{\circ} \mathrm{C}$ ). Given the small dimensions of the gap, the current approach requires very tight tolerances with regard to the pin outside diameter, the capsule inside diameter, and placing the rodlet within the capsule in a concentric manner. Moreover, the small gas-filled gap make fuel pin temperatures very sensitive to ATR power levels.

Based on these lessons learned, a number of steps were taken to mitigate future problems:

1. New tests were designed with individually encapsulated rodlets, so that failure of one rodlet has no effect on the other rodlets residing in the same basket.

2. Improved methods were developed for gun drilling of the capsule inner diameters and increased, three-dimensional measurement requirements were implemented for inspection of fabricated capsules. For example, originally only the ends of a capsule were characterized but subsequently measurements are now taken over the entire capsule length.

3. A honing machine was procured for capsule fabrication that allows the inside diameter to be controlled to tolerances of about $0.001 \mathrm{in}$.

4. Additional checks for straightness of the cladding tubes were implemented to minimize the potential for bowed rodlets. 
5. Cycle-by-cycle thermal analyses had been performed informally, but now these analyses are subject to the formal INL engineering process and documented accordingly.

6. INL contracted with Utah State University to characterize and quantify the thermal conductance of the small gas gaps used in the AFC irradiation experiments.

7. To better account for the inherent uncertainties of the experiments, the target for linear heat generation rate was lowered from $350 \mathrm{~W} / \mathrm{cm}$ to $325 \mathrm{~W} / \mathrm{cm}$ to provide additional margin against melting of the fuel or the formation of low-melting point eutectics.

While these measures have helped, results from postirradiation exams still indicate difficulties in the experimental design. For example, Figure 6 shows recent metallography from a sodium-bonded, solid $\mathrm{U}-10 \mathrm{Zr}$ fuel alloy with a smear density of 75 percent that indicates desired rodlet temperatures were exceeded and that the temperature distribution within the pin was asymmetric. ${ }^{9}$ These results suggest that a continued focus on the experimental design is warranted so that uncertainties in rodlet temperatures can be further reduced. One approach recommended by the outside review panel ${ }^{8}$ was to employ a design with both an inner and outer capsule. The gap between the rodlet and the inner capsule would be sodium-bonded, while the gap between the inner and outer capsules would be helium-bonded. The potential advantage of this design is that the high thermal conductivity of the bond sodium will reduce variations in pin temperatures caused by eccentricities in the helium-filled gas gap.

To better characterize the current capsule design and to test alternative approaches, developing the capability to test electrically-heated versions of different capsule designs should be explored. Obvious advantages to this approach are that power levels and temperatures can be much better characterized than in an irradiation test and that different capsule designs can be explored at far less cost than if the testing was performed in the ATR. Another possible approach is to use an instrumented capsule design similar to what has been used in the TMIST program ${ }^{10}$ and for Advanced Gas Reactor fuel experiments ${ }^{11}$ (see Figure 7). In these designs, the ratio of helium-to-neon in the gap can be varied to control temperatures in-reactor based on the reading of a thermocouple. Unfortunately, this approach will likely require the use of larger irradiation positions (such as a small B position) in the ATR, which in turn will cause scheduling difficulties. Moreover, because the in-reactor lifetimes of thermocouples are typically limited, this approach would only be workable for experiments where the desired end-of-life burnups are relatively low. Regardless of whether an improved capsule design is developed or simply that the current design is better characterized, out-of-reactor testing will increase the likelihood of achieving desired in-reactor conditions and reduce the uncertainty in the interpretation of data obtained from postirradiation examinations. 


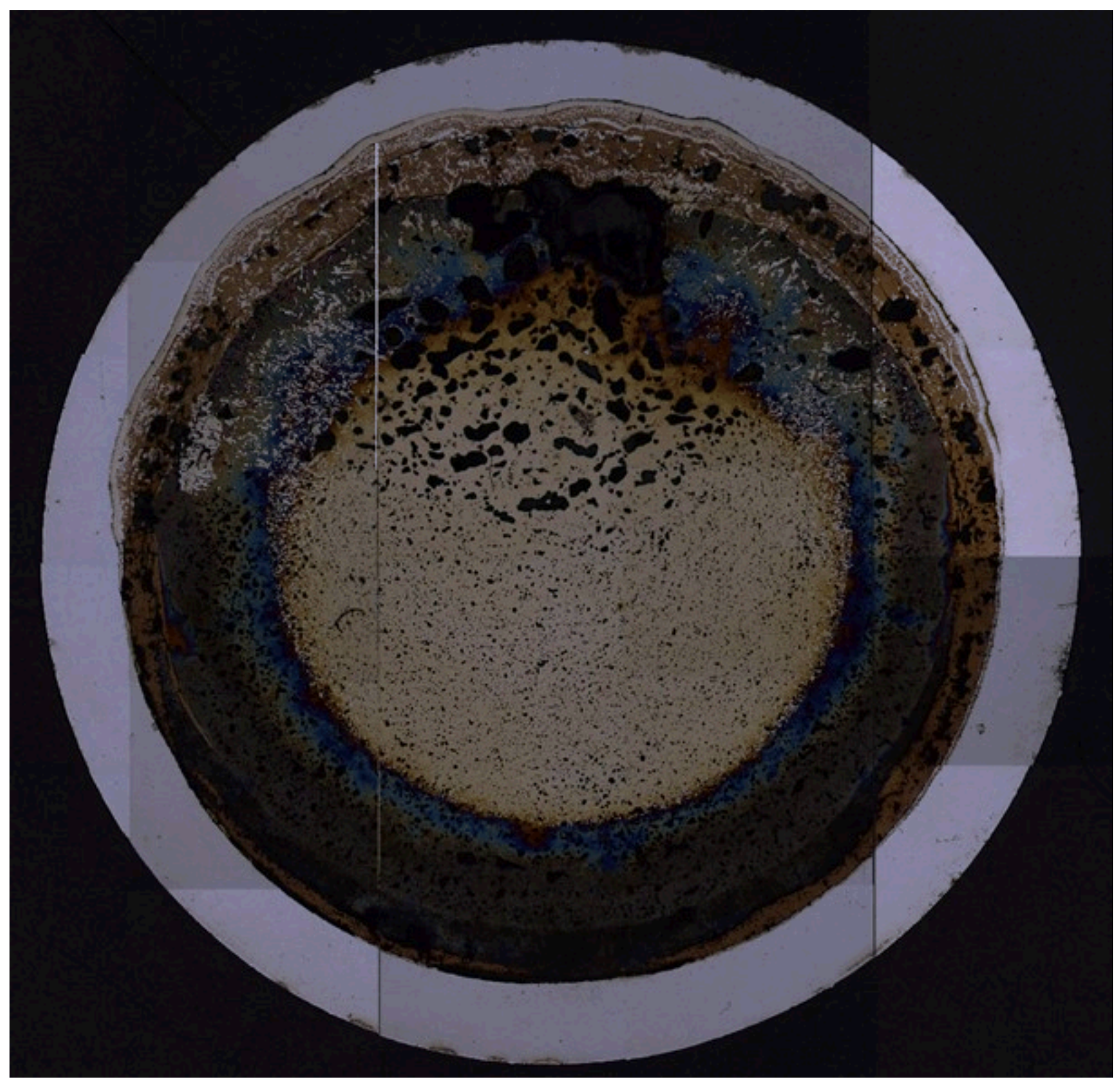

Figure 6. Micrograph of a sodium-bonded, solid U-10Zr fuel alloy with a smear density of 75 percent that was tested in the ATR and was recently subjected to post-irradiation examinations [9]. The micrograph shows melting around the outside rim of the fuel, evidence of an axisymmetric temperature distribution, and extensive fuel/cladding chemical interaction on the (apparently) hotter side of the pin. Given that the behavior of this fuel system is very well-characterized, the result is a recent example that illustrates the difficulties of using a thin gas-filled gap between the rodlet and the capsule to produce fuel pin temperatures that are prototypical of a sodium-cooled fast reactor. Ways of reducing the uncertainties in fuel pin temperatures will be explored so that the results obtained from the testing can be assessed with greater confidence. 


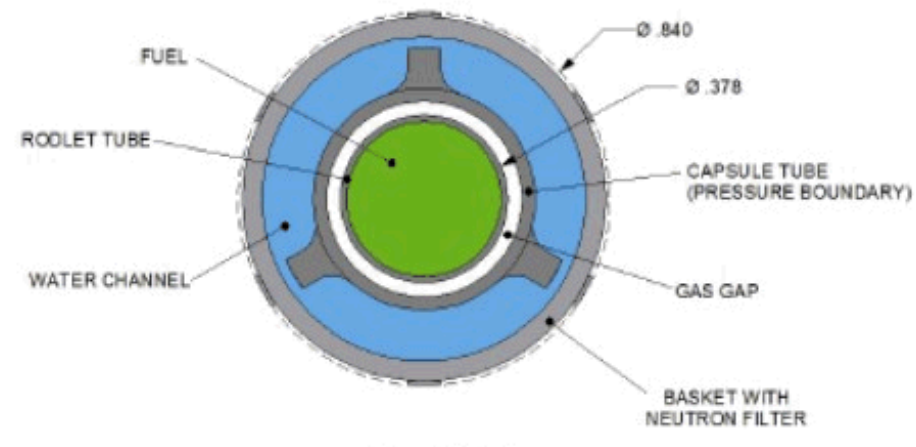

LDF-1 DESIGN

(a)

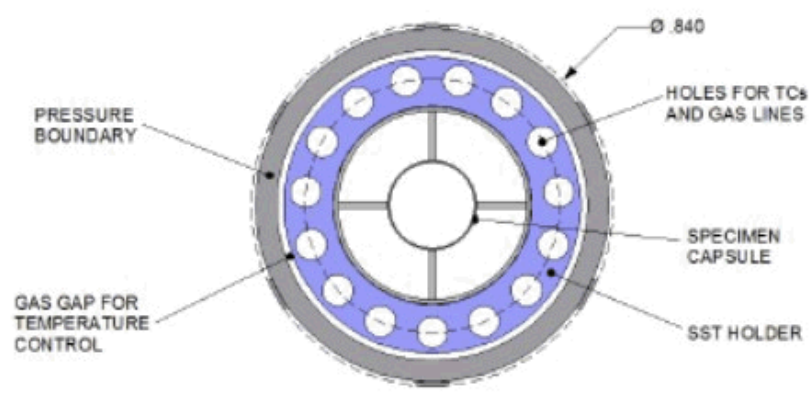

TMIST DESIGN

(b)

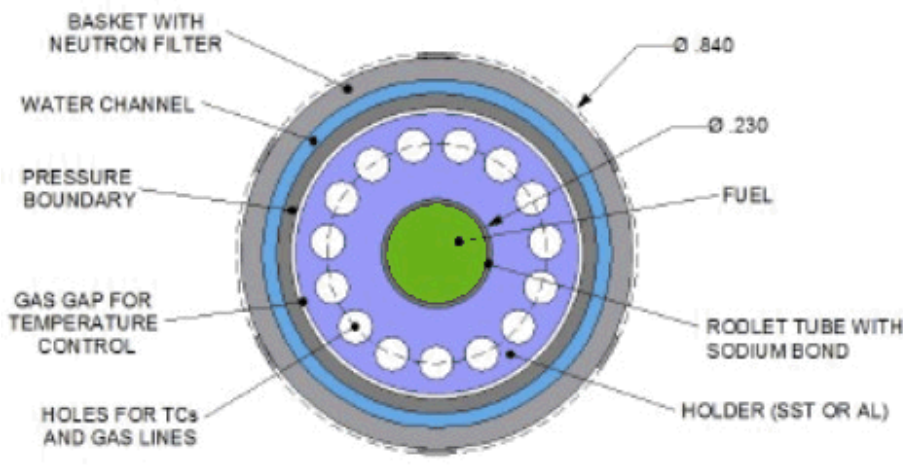

POSSIBLE LEADOUT CONFIGURATION

(c)

Figure 7. (a) Drawing of the current capsule design for testing metallic fast reactor fuels in the ATR; (b) Schematic of the instrumented capsule for the TMIST program; and (c) A potential instrumented design for testing metallic fuels. 


\subsection{Solid, Sodium Bonded Fuel with Reduced Smear Density}

As discussed previously, reduced smear density designs (in this context, smear densities less than 75 percent) provide greater volume to accommodate fuel swelling and the accumulation of fission products and can be expected to increase the amount of fission gas released to the plenum. Relative to a low smear density annular fuel design, the advantage of a sodium-bonded solid fuel design is improved effective thermal conductivity of the fuel. A potential disadvantage, however, is that the relatively large gap between the outside of the fuel and the inside of the cladding at beginning-of-life suggests that there will be larger amounts of axial extension of the fuel when compared to annular designs or even to solid fuel designs with higher smear density.

Figure 8 shows neutron radiographs of low smear density (55 percent) pins taken to about 2-4 at.\% burnup. ${ }^{12}$ Note that the sodium-bonded, solid fuel designs exhibited liftoff, extensive axial deformation, and ended irradiation with unusual, asymmetric distributions of fuel within the cladding; in contrast, the annular fuel design shows little evidence of axial extension of the fuel and the distribution of fuel within the pin appears to be relatively uniform. The features associated with the low smear density, solid fuel designs will result in substantial increases in uncertainties from the reactor physics point of view, and the uneven distribution of fuel raises concerns about fuel slumping that will be difficult to address. For these reasons, the pursuit of sodium-bonded, solid fuel designs with low smear density will be discontinued.

\subsection{Sodium-Free Annular Fuel Designs}

Sodium-free annular fuel has the potential to reduce disposal costs for once-through metallic fast reactor fuel. To ensure the effective transport of thermal energy from the fuel to the coolant, however, either a helium bond or a mechanical bond is required. In the case of helium-bonded annular fuel, a disadvantage of this approach is that it requires extremely tight tolerances on fuel outside diameter and cladding inside diameter. In contrast, fuel designs that employ sodium-bond can be fabricated with relatively loose tolerances and are more robust in the sense that the presence of the sodium provides a much greater assurance that adequate heat transfer will occur. Furthermore, infiltration of bond sodium into the open porosity of swollen metallic fuels can serve to increase the effective thermal conductivity of the fuel and offset some of the degradation of that property generally associated with irradiation. However, taking advantage of the presence of sodium in a reactor design may be challenging since it is difficult to characterize with any precision how much of the bond sodium infiltrates the fuel at higher burnups.

Reduced smear density (55 percent) annular fuel pins that used either U-10Zr, U-4Pd-10Zr, or U-10Mo were tested as part of the AFC-3A and AFC-3B experiments ${ }^{12}$ (note, however, that only low burnups results are currently available). In the case of the U-10Zr alloys, the overall performance of the fuel elements appears to be satisfactory, although there are some concerns associated with increased porosity and FCCI at the fuel/cladding interface in these experiments (see Figure 9). Continued investigations and testing of annular designs is recommended along with evaluating methods to mitigate concerns regarding reduced thermal conductivity and enhanced fuel/cladding chemical interactions.

\subsection{U-10Mo Alloy Fuel}

Principal advantages of U-10Mo is stabilization of the $\gamma$-phase, the potential for reduced lanthanide migration, and an increase in fuel thermal conductivity and solidus temperature. ${ }^{1}$ Recent metallography from Reference 12, however, has shown substantial increases in fuel/cladding interactions relative to U-10Zr fuels (see Figure 10); note that this is a fundamental incompatibility between U-10Mo and stainless steel cladding, apart from any additional interaction that may occur due to lanthanide fission products. Further development of this alloy should be discontinued unless modeling shows that U-10Mo with a liner provides a substantial benefit over fuel designs that employ either U-10Zr or unalloyed fuel. 
AFC-3B

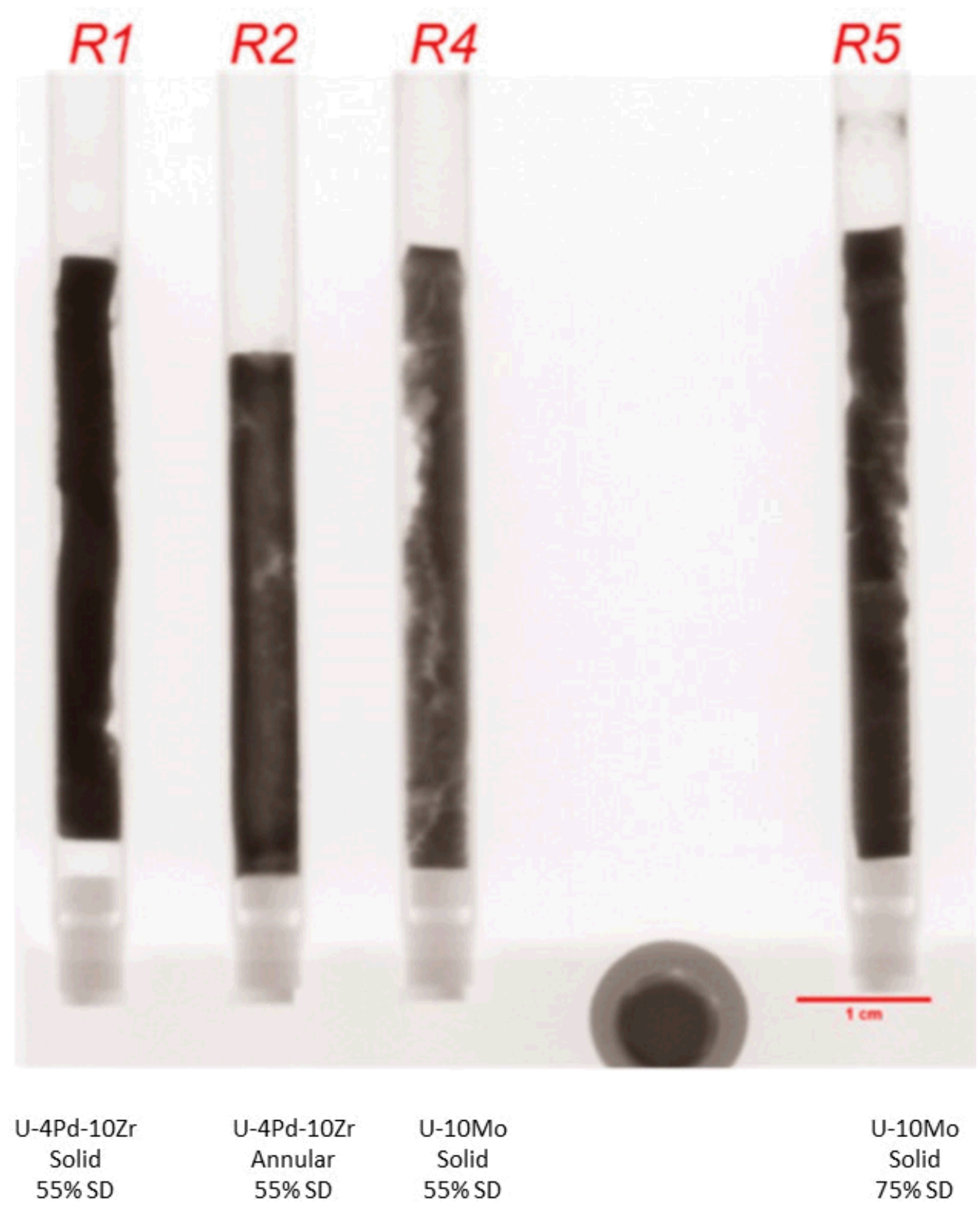

Figure 8. Neutron radiographs of low smear density (55 percent) pins taken to burnups of about 2-4 atom percent. ${ }^{12}$ Note that the sodium-bonded, solid fuel designs exhibited liftoff, extensive axial deformation, and had unusual distributions of fuel within the cladding; in contrast, the annular design shows little evidence of axial extension of the fuel and the distribution of fuel within the pin appears to be relatively uniform. The features associated with the solid fuel designs will result in substantial increases in uncertainties from the reactor physics point of view, and the uneven distribution of fuel raise concerns about fuel slumping that will be difficult to address. For these reasons, the pursuit of sodium-bonded solid fuel designs with low smear density (e.g., less than 75 percent) will be discontinued. 


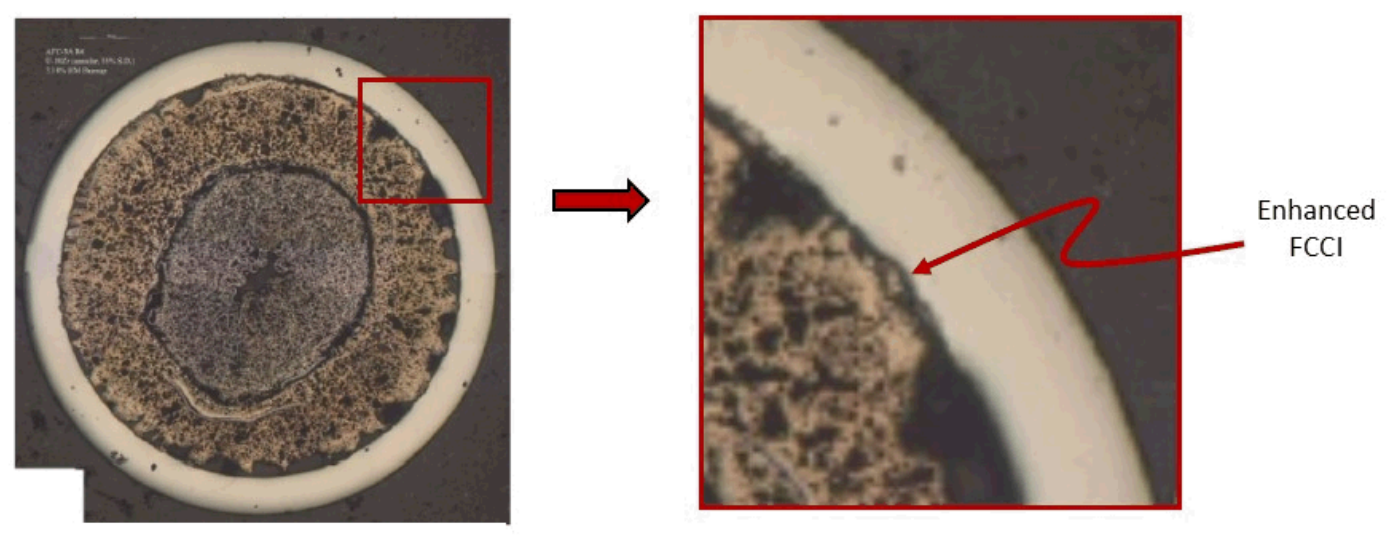

Figure 9. Micrographs of a rodlet with annular U-10Zr, a smear density of 55 percent, and without the use of sodium bond. ${ }^{12}$ Note the region of high porosity (and therefore degraded thermal conductivity) along the fuel/cladding interface and the area that shows accelerated fuel/cladding chemical interaction. Overall, however, performance of the low smear density, annular designs with U-10Zr appears to be satisfactory. Continued investigations and testing of annular designs is recommended along with evaluating methods to mitigate concerns regarding reduced thermal conductivity and enhanced fuel/cladding chemical interactions.

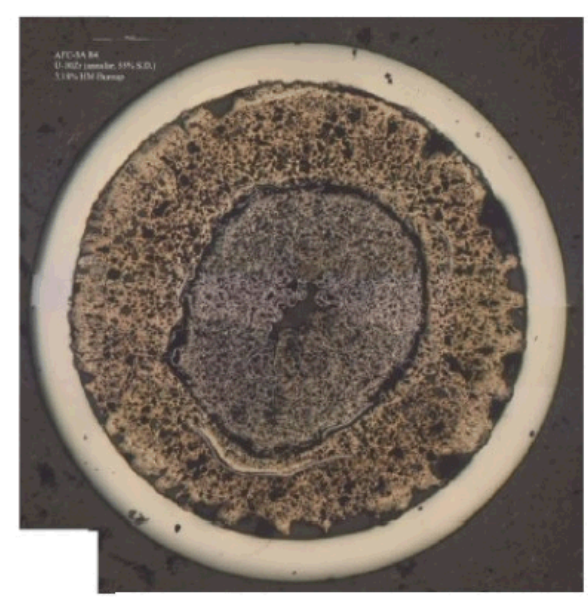

(a)

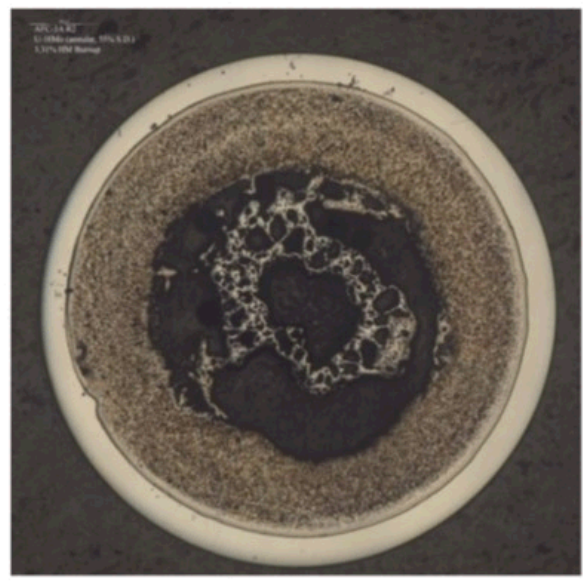

(b)

$$
\begin{gathered}
\text { AFC-3A Rodlet } 4 \\
\text { U-10Zr } \\
\text { Annular } \\
\text { 55\% Smear Density }
\end{gathered}
$$

Figure 10. Micrographs rodlets with (a) U-10Zr; and (b) U-10Mo, each with an initially annular configuration, a smear density of 55 percent, and free from the use of sodium bond. ${ }^{12}$ Compared with the U-10Zr alloy, the fuel pin with U-10Mo shows large amounts of fuel/cladding chemical interaction and possibly centerline melting of the fuel. The U-10Zr pin may have avoided melting because the migration of zirconium towards the pin center (and the corresponding migration of uranium away from the pin center) has the effect of increasing the solidus temperature near the center of the pin and moving power towards the fuel/cladding interface. Based on these results, the testing of U-Mo alloys for fast reactor applications will be continued only after evaluating designs that employ liners. 
The experience with U-10Mo also underscores the importance of using out-of-reactor testing to guide the experimental design of in-reactor tests. As an example, the following is an excerpt from Reference 13, dated December, 2010:

"At $700{ }^{\circ} \mathrm{C}$, the reaction zone into the cladding was at most a few hundred microns for the $\mathrm{Zr}$ bearing fuel, however, in the case of the Mo containing fuels the reaction appeared to be several millimeters into the cladding and induced near complete melting of the fuel." (emphasis added)

The out-of-reactor experiments indicated that U-10Mo should not have been used in conjunction with HT-9 cladding unless a diffusion barrier between the fuel and cladding was incorporated into the fuel element design.

\subsection{Targeted Fuel Alloy Additions}

The basic idea behind minor alloying additions is that elements such as indium, tin, thallium, and palladium tend to form thermodynamically stable compounds with the lanthanides ${ }^{1,4}$ (see Figure 11). These elements, therefore, have the potential to tie-up the lanthanide fission products that are associated with fuel/cladding chemical interactions, particularly in U-10Zr alloys. A concern, however, is that reactions of potential gettering agents with zirconium are almost as favorable. For U-10Zr alloys in particular, reactions between a gettering element and zirconium would imply that the lanthanides would not be tied up and would, therefore, be free to attack the cladding.

To explore this issue, out-or-reactor experiments were performed with U-15Zr alloys containing varying amounts of palladium and lanthanide fission products. ${ }^{4}$ Figure 12a provides a micrograph taken from Reference 4 that shows a number of different kinds of precipitates that have formed in a U-15Zr-3.86Pd4.3 Ln alloy, where $\mathrm{Ln}$ is define as an alloy composed of four lanthanides $(53 \mathrm{Nd}-25 \mathrm{Ce}-16 \mathrm{Pr}-6 \mathrm{La}$, all percentages in wt\%). In addition, Figure 12b provides a table taken from Reference 4 that shows the compositions of the various precipitates (in atom fractions) as determined by energy dispersive $\mathrm{x}$-ray analysis. The red box highlights precipitates that contain lanthanides while the blue box indicates compounds that are free of lanthanides. Note that the majority of the palladium is in the lanthanide-bearing precipitates and the excess palladium is found in the compounds without lanthanides. The results indicate that the palladium does tie up the lanthanides preferentially to zirconium, which in turn suggests that palladium should perform well as a lanthanide getter.

Recent metallography from the AFC-3A and AFC-3B tests, however, indicate that palladium may not perform well as a fission product getter well in-reactor. (a) A micrograph taken from Reference [4] that shows a number of different kinds of precipitates that have formed in a U-15Zr-3.86Pd-4.3Ln alloy, where $\mathrm{Ln}=53 \mathrm{Nd}-25 \mathrm{Ce}-16 \mathrm{Pr}$-6La (all percentages are in wt\%). (b) A table provided from Reference [4] that shows the compositions of the various precipitates (in atom fractions) as determined by energy dispersive X-ray analysis. The red box highlights precipitates that contain lanthanides while the blue box indicates compounds that are free of lanthanides. The results indicate that the palladium does tie up the lanthanides preferentially to zirconium, which in turn suggests that palladium should perform well as a lanthanide getter. 


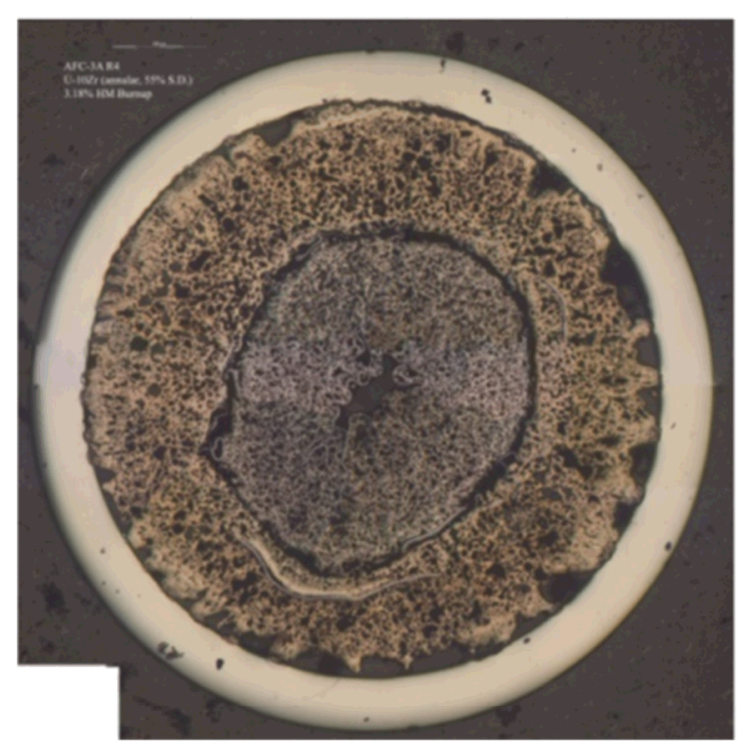

U-10Zr

Annular

$55 \%$ SD

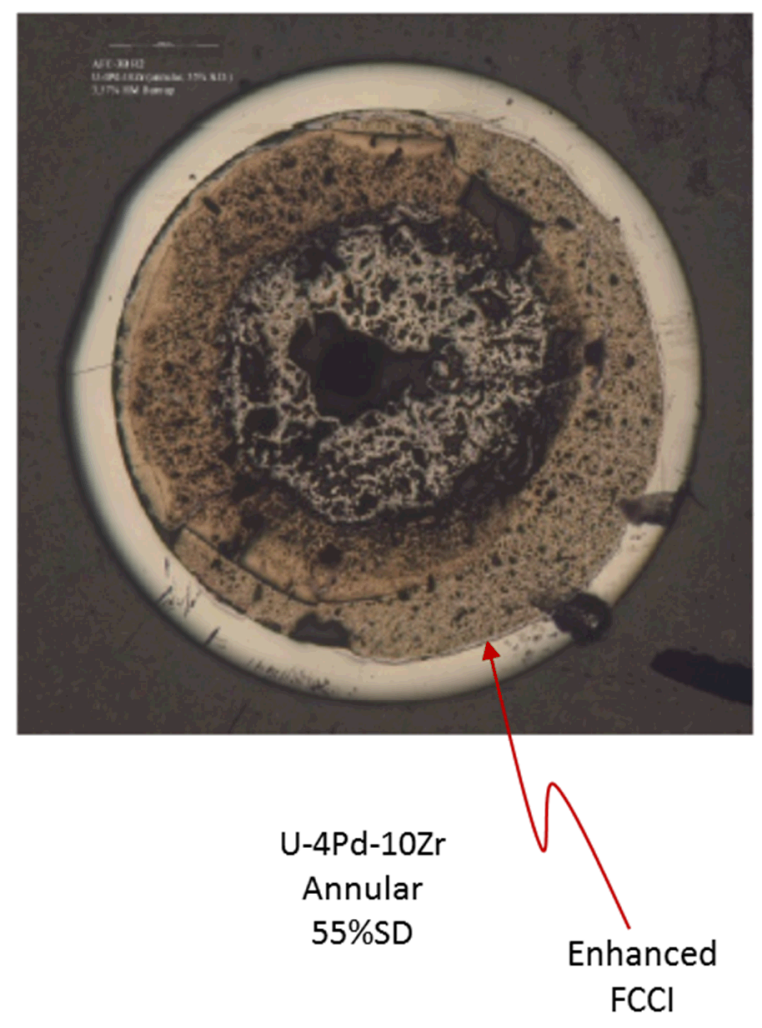

(b)

Figure 13 shows micrographs of annular, 55 percent smear density fuel pins with either (a) U-10Zr or (b) U-4Pd-10Zr. ${ }^{12}$ Ironically, the pin with the palladium appears to have more FCCI than the standard U$10 \mathrm{Zr}$ alloy. Preliminary work ${ }^{14}$ indicates that most of the zirconium and palladium migrated to the center of the pin and that there was, therefore, little palladium left to getter fission products near the fuel/cladding interface. The palladium appears to have reacted and migrated with the zirconium prior to the availability of lanthanide fission products that are gradually produced as burnup increases. Once compounds of zirconium and palladium formed, there maybe be an insufficient thermodynamic driving force for reactions between the palladium and the lanthanides. Based on these preliminary results, out-ofreactor development for alternative candidates for fission product getters will continue, but more extensive modeling studies will be required before additional in-reactor testing is pursued. 


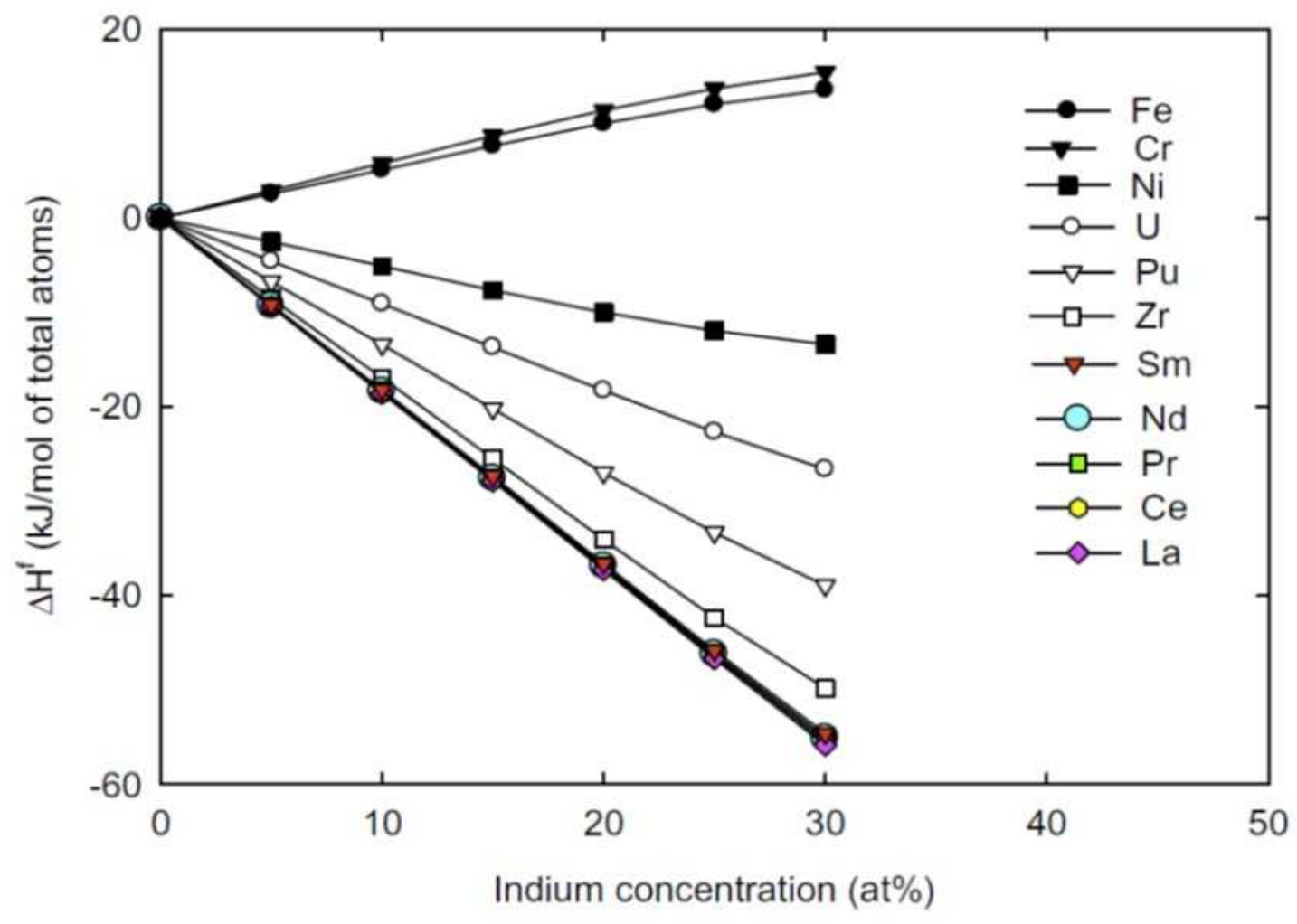

Figure 11. A plot of the enthalpy of formation for various elements reacting to form indium-bearing compounds as a function of indium concentration. ${ }^{1}$ The plot shows that although the formation of lanthanide compounds with a potential getter (indium, in this case) is energetically favored, the formation of zirconium compounds with the getter is almost as favorable. Given that zirconium is the most common alloying element for metallic fast reactor fuels, a concern is that the gettering agent might react with zirconium and not the lathanides. 


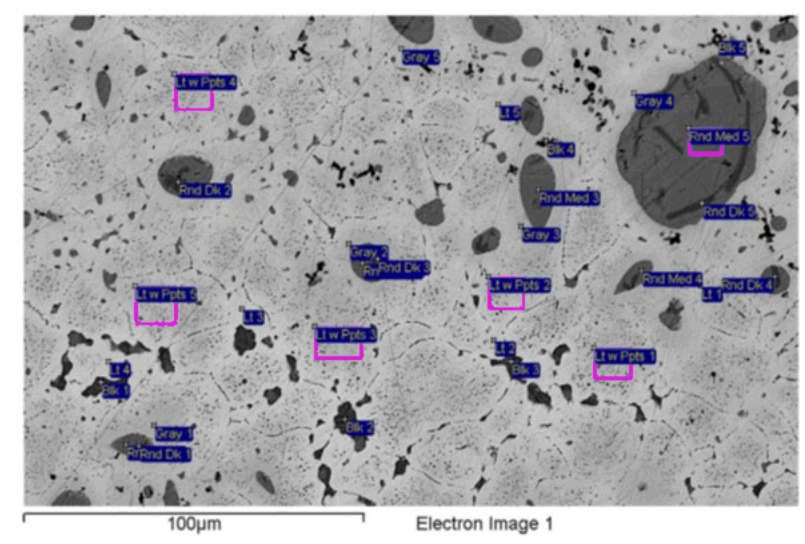

(a)

\begin{tabular}{|llllllll|}
\multicolumn{7}{l}{ Atom fractions, by standardless energy dispersive X-ray analysis, for Alloy } & 6 , Fig. 3. \\
\hline Spectrum & Zr & Pd & La & Ce & Pr & Nd & U \\
\hline Lt 1 & 0.30 & 0.00 & 0.00 & 0.00 & 0.00 & 0.00 & 0.70 \\
Lt 2 & 0.19 & 0.00 & 0.00 & 0.00 & 0.00 & 0.00 & 0.81 \\
Lt 3 & 0.20 & 0.00 & 0.00 & 0.00 & 0.00 & 0.00 & 0.80 \\
Lt 4 & 0.19 & 0.00 & 0.00 & 0.00 & 0.00 & 0.00 & 0.81 \\
Lt 5 & 0.29 & 0.02 & 0.00 & 0.00 & 0.00 & 0.00 & 0.68 \\
Lt w Ppts 1 & 0.35 & 0.06 & 0.00 & 0.00 & 0.00 & 0.00 & 0.59 \\
Lt w Ppts 2 & 0.33 & 0.05 & 0.00 & 0.00 & 0.00 & 0.00 & 0.63 \\
Lt w Ppts 3 & 0.35 & 0.05 & 0.00 & 0.00 & 0.00 & 0.00 & 0.60 \\
Lt w Ppts 4 & 0.36 & 0.04 & 0.00 & 0.00 & 0.00 & 0.00 & 0.60 \\
Lt w Ppts 5 & 0.33 & 0.05 & 0.00 & 0.00 & 0.00 & 0.00 & 0.62 \\
Gray 1 & 0.36 & 0.02 & 0.00 & 0.00 & 0.00 & 0.00 & 0.62 \\
Gray 2 & 0.40 & 0.00 & 0.00 & 0.00 & 0.00 & 0.00 & 0.60 \\
Gray 3 & 0.42 & 0.00 & 0.00 & 0.00 & 0.00 & 0.00 & 0.58 \\
Gray 4 & 0.37 & 0.02 & 0.00 & 0.00 & 0.00 & 0.00 & 0.60 \\
Grav 5 & 0.36 & 0.03 & 0.00 & 0.00 & 0.00 & 0.00 & 0.60 \\
\hline BIK 1 & 0.61 & 0.34 & 0.00 & 0.01 & 0.00 & 0.00 & 0.05 \\
Blk 2 & 0.60 & 0.35 & 0.00 & 0.01 & 0.00 & 0.00 & 0.05 \\
Blk 3 & 0.55 & 0.30 & 0.00 & 0.03 & 0.01 & 0.01 & 0.10 \\
Blk 4 & 0.85 & 0.04 & 0.00 & 0.01 & 0.01 & 0.02 & 0.06 \\
Blk 5 & 0.94 & 0.00 & 0.00 & 0.00 & 0.00 & 0.01 & 0.06 \\
Rnd Med 1 & 0.00 & 0.52 & 0.05 & 0.08 & 0.14 & 0.21 & 0.00 \\
Rnd Med 2 & 0.00 & 0.52 & 0.04 & 0.06 & 0.15 & 0.22 & 0.00 \\
Rnd Med 3 & 0.00 & 0.51 & 0.04 & 0.08 & 0.15 & 0.22 & 0.00 \\
Rnd Med 4 & 0.00 & 0.51 & 0.05 & 0.08 & 0.14 & 0.22 & 0.00 \\
Rnd Med 5 & 0.00 & 0.51 & 0.05 & 0.08 & 0.14 & 0.22 & 0.00 \\
Rnd Dk 1 & 0.00 & 0.17 & 0.10 & 0.15 & 0.23 & 0.35 & 0.00 \\
Rnd Dk 2 & 0.00 & 0.03 & 0.08 & 0.15 & 0.29 & 0.44 & 0.01 \\
Rnd Dk 3 & 0.00 & 0.09 & 0.09 & 0.14 & 0.27 & 0.41 & 0.00 \\
Rnd Dk 4 & 0.00 & 0.18 & 0.10 & 0.12 & 0.21 & 0.37 & 0.02 \\
Rnd Dk 5 & 0.00 & 0.05 & 0.10 & 0.12 & 0.28 & 0.45 & 0.00 \\
\hline \hline
\end{tabular}

(b)

Figure 12. (a) A micrograph taken from Reference [4] that shows a number of different kinds of precipitates that have formed in a U-15Zr-3.86Pd-4.3Ln alloy, where Ln=53Nd-25Ce-16Pr-6La (all percentages are in wt\%). (b) A table provided from Reference [4] that shows the compositions of the various precipitates (in atom fractions) as determined by energy dispersive $X$-ray analysis. The red box highlights precipitates that contain lanthanides while the blue box indicates compounds that are free of lanthanides. The results indicate that the palladium does tie up the lanthanides preferentially to zirconium, which in turn suggests that palladium should perform well as a lanthanide getter. 


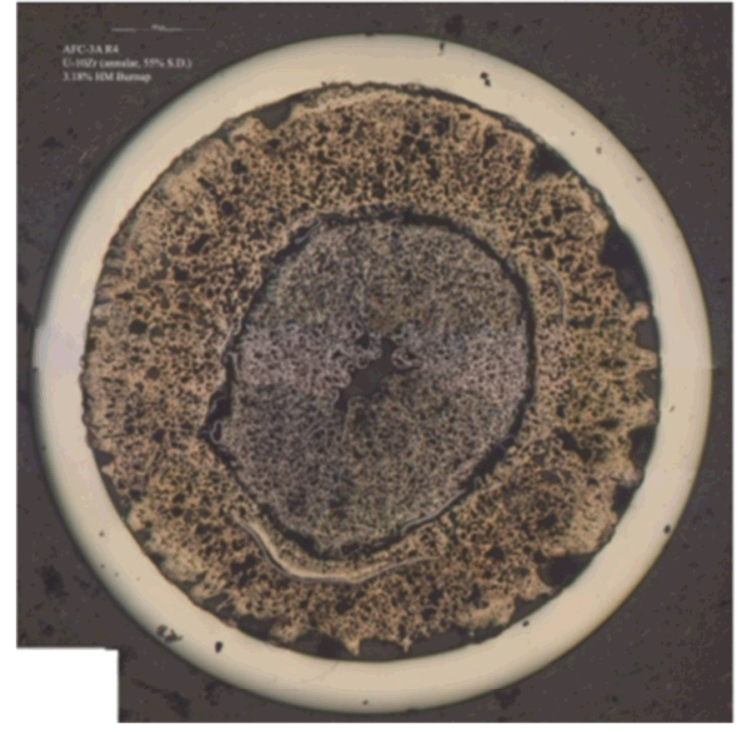

$\mathrm{U}-10 \mathrm{Zr}$

Annular

$55 \%$ SD

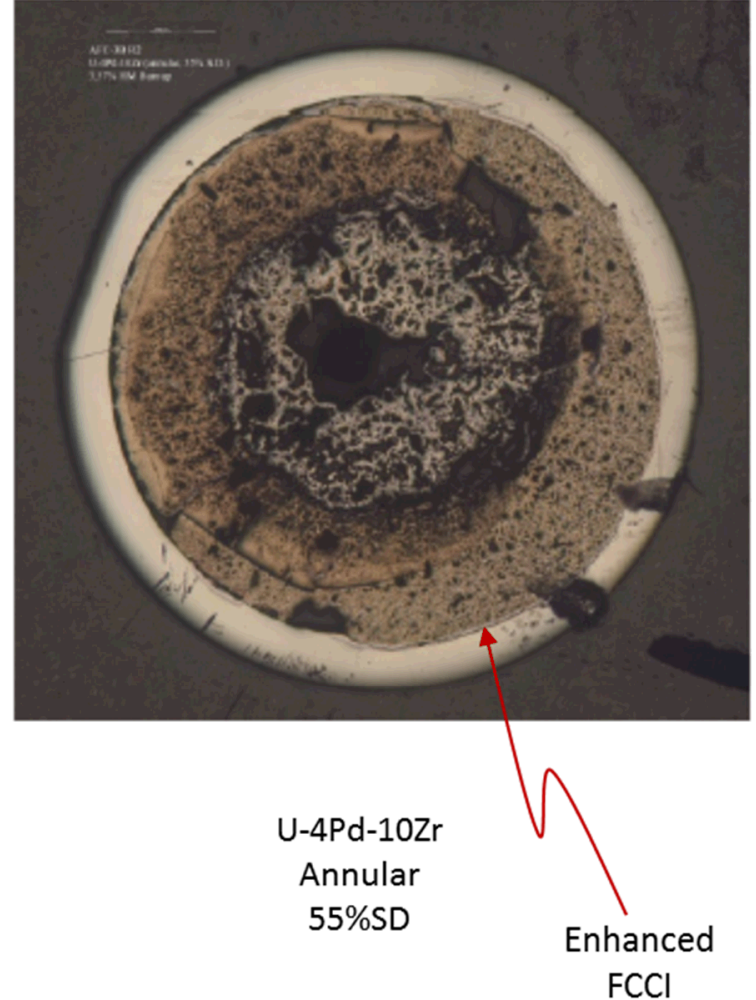

(b)

Figure 13. Micrographs of annular, 55 percent smear density fuel pins with either (a) U-10Zr; or (b) U$4 P d-10 Z r{ }^{12}$ Ironically, the pin with the palladium appears to have more fuel/cladding chemical interaction than the standard U-10Zr alloy. Preliminary work $^{14}$ indicates that most of the zirconium and palladium migrated to the center of the pin. There was therefore little palladium left to getter fission products near the fuel/cladding interface. The palladium appears to have reacted and migrated with the zirconium prior to the availability of lanthanide fission products. Once compounds of zirconium and palladium formed, there maybe be an insufficient thermodynamic driving force for reactions between the palladium and the lanthanides.

\section{WORK BY OTHER INSTITUTIONS}

The Russians (Research Institute of Atomic Reactors [RIAR]) have developed an extensive program for metallic fast reactor fuels. The objective of their work is to develop "heterogeneous cores" (i.e., mixing of both $\mathrm{UO}_{2}$ and metallic fuel) for their BN series of sodium-cooled fast reactors. ${ }^{15-17}$ Although the initial emphasis appears to be focused on blanket pins that take advantage of the higher heavy metal loading of metallic fuels, ${ }^{15}$ more recent studies indicate that they are also interested in metallic fuel for powerproducing fuel elements. ${ }^{17}$ The effort is quite extensive in comparison to the current U.S. program, involving about 100 fuel assemblies and over 3000 pins.

Through the course of their work, the Russians have apparently investigated a variety of fuel shapes (see Figure 14). To reduce fuel/cladding chemical interactions, they have studied tungsten and chromium liners on the inside of cladding tubes and uranium oxide or uranium carbide coating on the exterior of the metallic fuel form. Although a number of different alloys were apparently investigated, the effort has 
been primarily focused on either pure uranium or uranium-plutonium alloys (up to $15 \mathrm{wt} \% \mathrm{Pu}$ ). Their investigations have been focused primarily on helium-bonded elements, apparently because the use of sodium bond is not possible in $\mathrm{BN}$ reactors because the gas plenum is located below the fuel column.

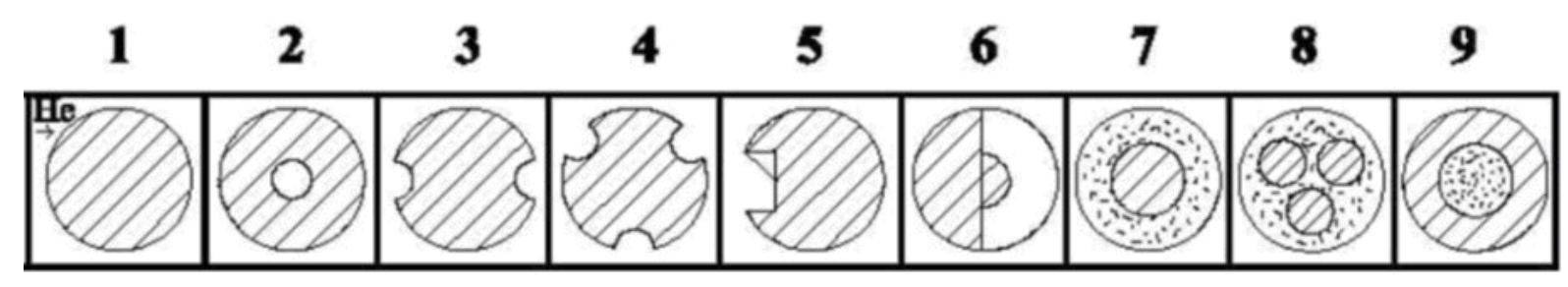

Figure 14. Shapes of fuel columns being explored by RIAR. ${ }^{15}$

The fuel shape that has apparently been investigated the most is of the slotted variety (see Figure 15). The driver for this particular design is almost certainly its ease of fabrication and is not related to fuel performance. The Russians correctly note, however, that once the volume associated with the slots are filled in, the effect of the initial fuel shape on fuel element behavior is likely to be negligible, although they have observed ovalization of fuel pins in colder regions of the core.

RIAR has also performed out-of-reactor mechanical testing on irradiated cladding and different fuel alloys (see Figure 16). For the uranium-plutonium alloy shown, the difference in yield strength between the fuel alloy and the cladding is particularly large. Although the out-of-reactor tests can only provide a qualitative guide to what in-reactor behavior might be, they do indicate that the cladding is substantially stronger than the fuel. This picture helps to explain why the Russians have also found that the effect of fuel alloy texture is not important for their designs, which is somewhat surprising given the strong effect that texture can have on the in-reactor growth of unconstrained uranium. The fact that the fuel element response was found to be independent of texture is significant, since it could potentially eliminate the need for heat treatment steps designed to randomize the crystallographic orientations in the fuel (e.g., in the case of pure uranium metal, quenching from the $\beta$ phase).

The Indians also have an active research effort into metallic fuels. Figure 17 shows a portion of a presentation by representatives from the Bhabha Atomic Research Centre (BARC) in Mumbai, India. ${ }^{18}$ The Indians appear to be pursuing technology based on both American and Russian experience. The design similar to American technology uses a sodium-bonded U-19Pu-6Zr alloy combined with a zirconium liner to prevent fuel/cladding chemical interaction. However, the Indians also appear to be pursuing a slotted fuel pin design with a mechanical bond, which is similar in many respects to the Russian efforts.

\section{EFFECT OF BOND SODIUM ON FUEL TEMPERATURES}

As can be seen from the above discussion, other institutions are pursuing fuel designs with and without the use of bond sodium. Given the interest in removal of the sodium bond for once-through applications, it seems useful to explore the impact of bond sodium on fuel system performance. A first step in that process is to estimate how much of the bond sodium infiltrates the porous fuel once it has swelled and made contact with the cladding.

Figure 18 shows the distribution of bond sodium and porosity in a 75 percent smear density, U-5Fs fuel element (the INL Experimental Breeder Reactor [EBR]-II Mark-II design) taken to a burnup of six at.\%. ${ }^{19}$ In the metallography, the dark areas correspond to regions of high sodium content. Comparisons of the 


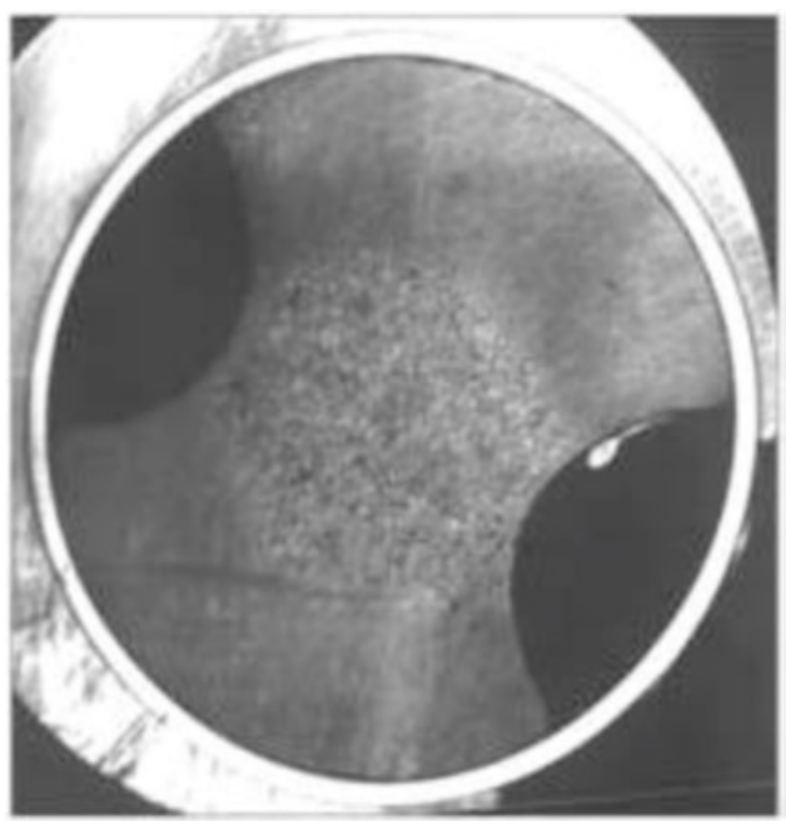

(a)

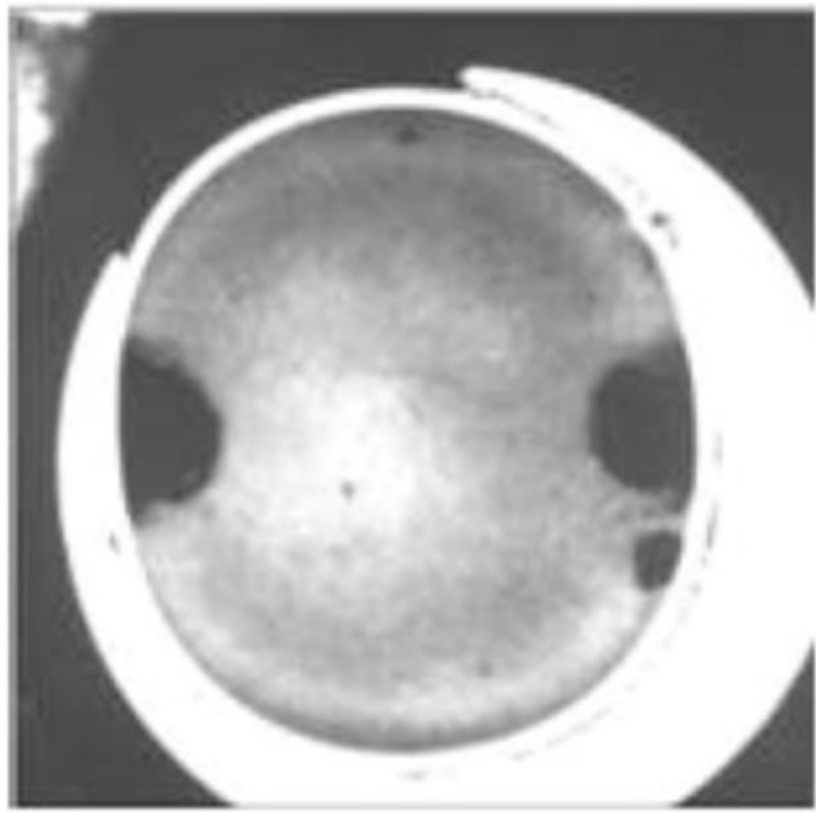

(b)

Figure 15. Micrographs from Russian work ${ }^{15}$ on metallic fuel that uses helium bonding, slots along the length of the fuel column to accommodate fission products, fuel compositions of either pure uranium or uranium-plutonium alloys, and a liner between the fuel and the cladding to reduce fuel/cladding chemical interactions. (a) Near the top of the core the burnup was apparently quite low so the original fuel geometry is evident; (b) lower in the core, ovalization of the fuel rod was observed. The Russians have an extensive effort in this area, having tested about 100 full-sized fuel assemblies more than 3000 fuel pins with metallic fuel. ${ }^{16}$ 


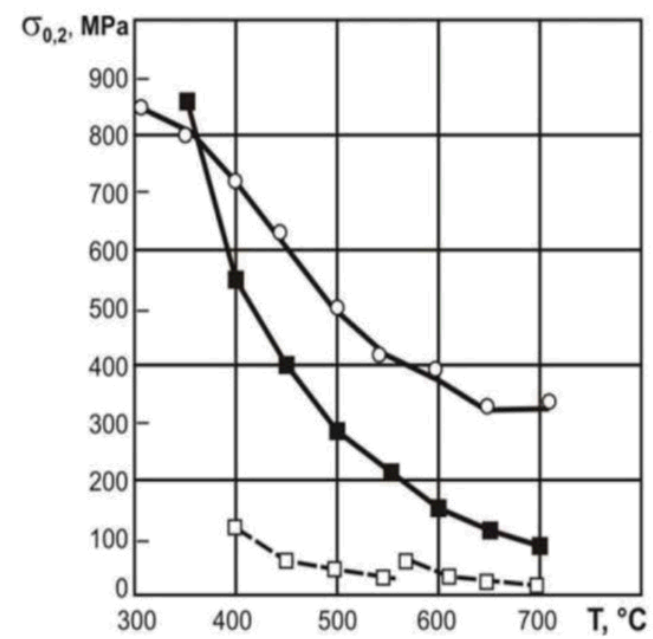

Fig 5. Dependence of yield strength of irradiated fuel and cladding materials on test temperature

$\circ-$ tensile tests of ring specimens (steel EI-847), $\mathrm{F}=61 \mathrm{dpa}, \mathrm{T}_{\text {test. }} \approx \mathrm{T}_{\text {ir. }}$ compression of cylindrical specimens U-13 Pu-11 Zr, Mo, Nb; B=6.3\% h.a. $\square-$ compression of cylindrical specimens $\mathrm{U}-15 \mathrm{Pu}, \quad \mathrm{B}=6.3 \%$ h.a.

Figure 16. Measurements of yield strength as a function of temperature for an irradiated stainless steel cladding and for fuel alloys of various compositions. ${ }^{17}$ Although such data do not characterize the inreactor response of these materials, they do provide some guidance as to the strength of the fuel relative to the cladding and the effects of alloying additions on fuel mechanical strength.
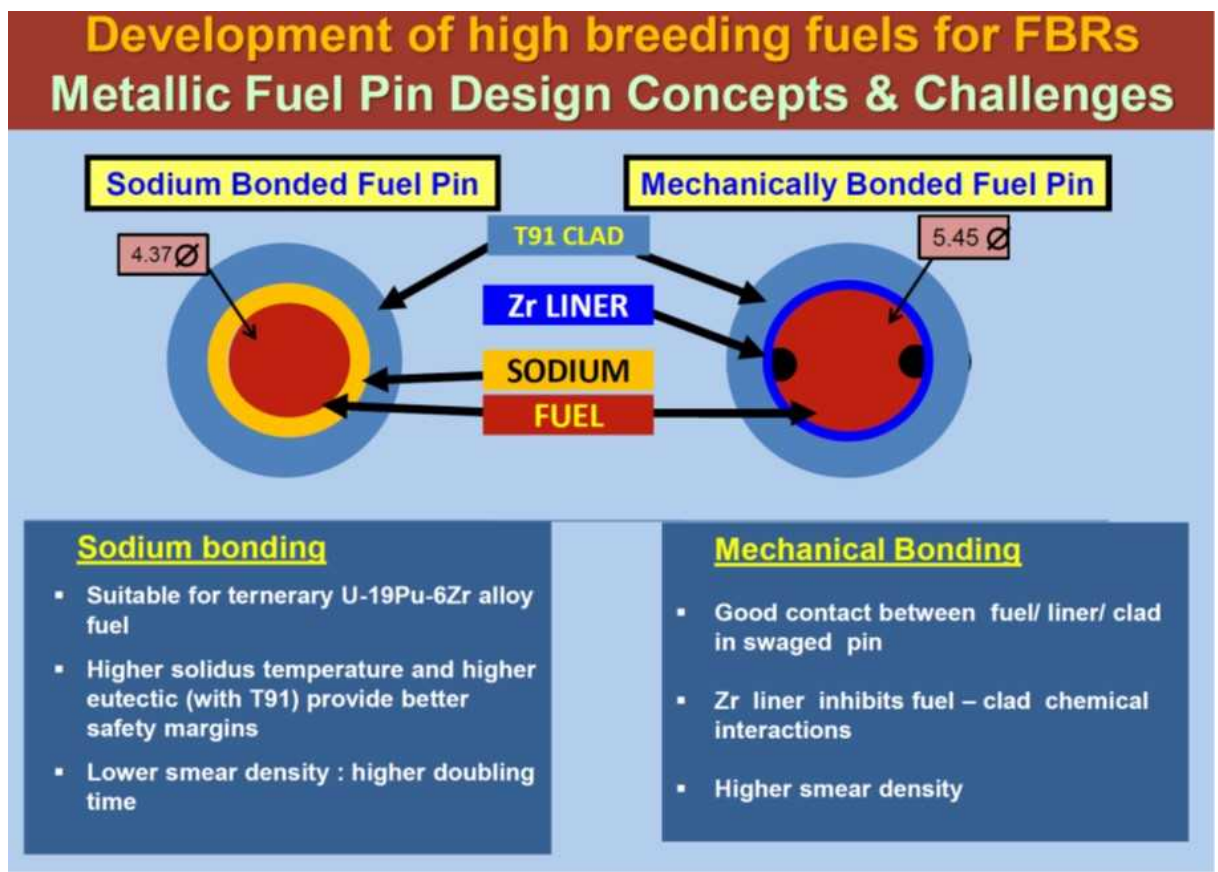

Figure 17. One slide taken from a presentation prepared by representatives of the Bhabha Atomic Research Centre (BARC) in Mumbai, India. ${ }^{18}$ The Indians appear to be pursuing technology based on both American and Russian experience. 


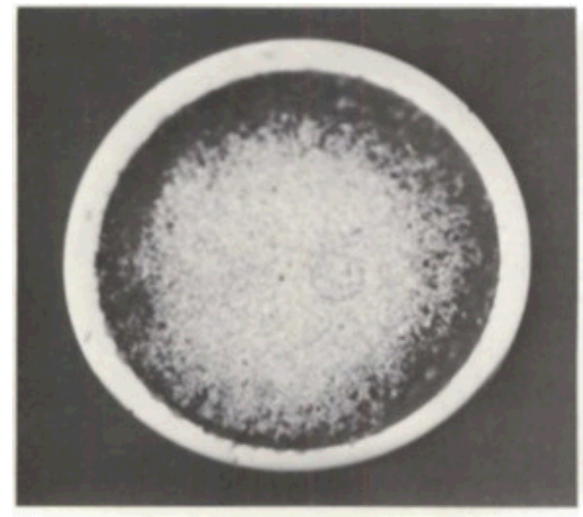

TOP OF PIN

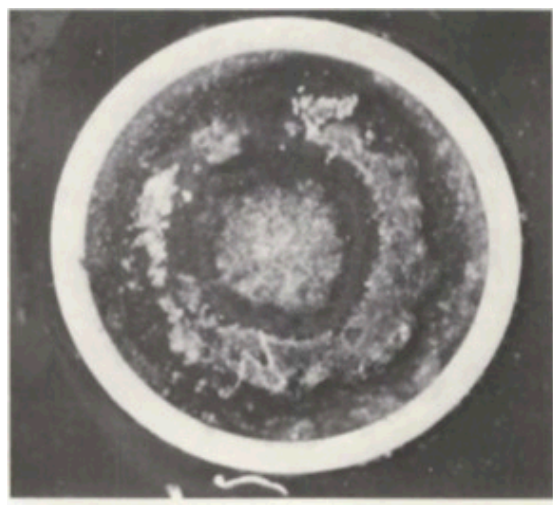

CORE MIDPLANE

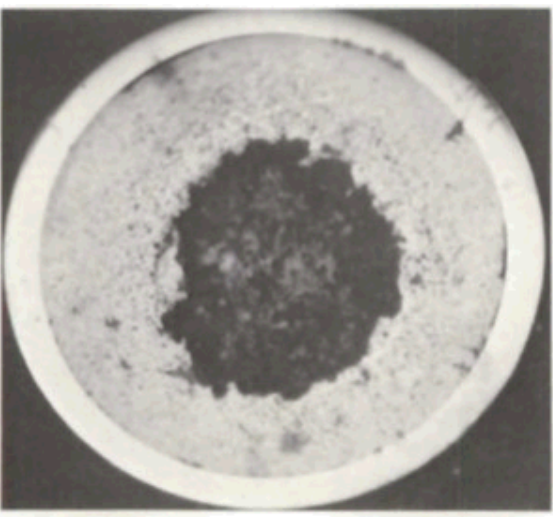

BOTTOM OF PIN

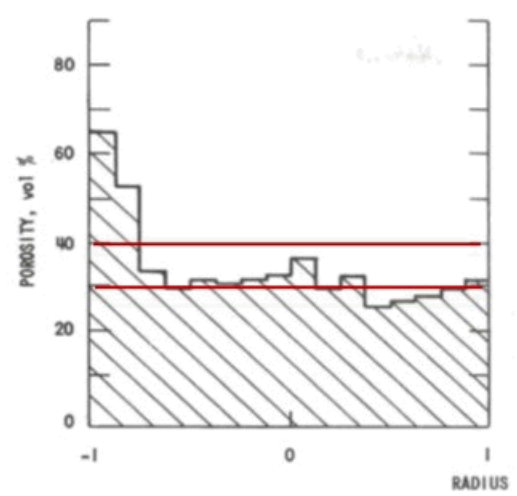

TOP OF PIK

(a)

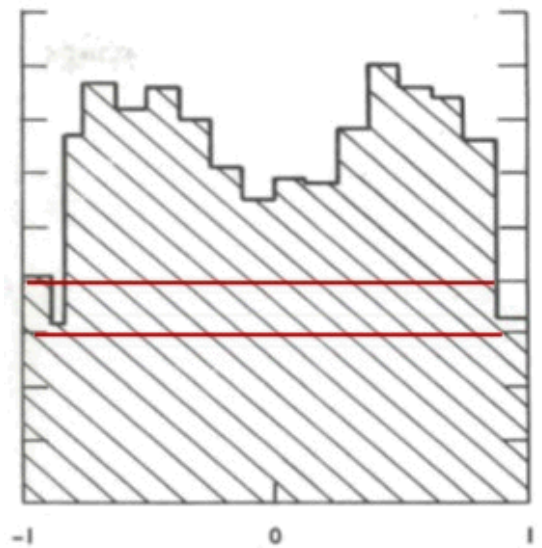

(b)

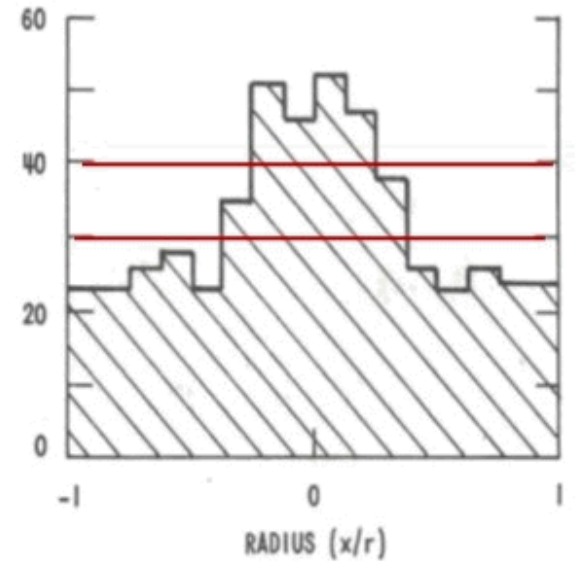

(c)

Figure 18. Figures taken from Reference 19 that show metallography of sodium infiltration into a metal fuel pin and the corresponding porosity distribution in the fuel (dark areas in the micrographs are indicative of high concentrations of sodium). Very roughly, the results indicate sodium infiltration where porosity is greater than about 30-40 percent. 
metallography indicate that the bond sodium infiltrates the fuel in regions where the pore volume fraction is greater than about 30 to 40 percent. For low smear density designs (e.g., smear densities less than 75 percent), these results suggest that greater amounts of the fuel would be infiltrated by bond sodium, though it is difficult to develop precise estimates of sodium infiltration based on this limited information.

The work of Bauer and Holland ${ }^{20}$ also provides additional experimentally-derived estimates of sodium infiltration. In this work, the amount of sodium infiltration was measured on a whole-pin basis by either radiographic or destructive examinations. As shown in Figure 19, Bauer and Holland provided estimates on the amount sodium infiltration for four different fuel alloys all having an initial smear density of 75 percent. Based on their work, roughly 20 to 40 percent of the porosity is estimated to be filled with sodium.

Whole-Pin Average Characteristics of Restructured Sodium-Bonded Metal Fuel*

\begin{tabular}{|l|l|l|l|l|}
\hline & \multicolumn{4}{|c|}{ Fuel Alloy } \\
\cline { 2 - 5 } & U-5 Fs & $\mathrm{U}-10 \mathrm{Zr}$ & $\mathrm{U}-8 \mathrm{Pu}-10 \mathrm{Zr}$ & $\mathrm{U}-19 \mathrm{Pu}-10 \mathrm{Zr}$ \\
\hline Radial swelling, $V_{r}$ & 1.33 & 1.38 & 1.38 & 1.38 \\
Axial swelling, $V_{a}$ & 1.045 & 1.085 & 1.065 & 1.025 \\
Swelled volume fraction, $P_{t o t}=1-1 /\left(V_{r} V_{a}\right)$ & 0.28 & 0.33 & 0.32 & 0.29 \\
Measured volume fraction sodium logged, $P_{\mathrm{Na}}$ & 0.06 & 0.13 & 0.08 & 0.08 \\
Gas-filled porosity, ${ }_{\mathrm{N}} P_{\mathrm{g}}=P_{t o t}-P_{\mathrm{Na}}$ & 0.22 & 0.20 & 0.24 & 0.21 \\
Maximum gas-filled porosity, $P_{g}(\max )=\left(P_{t o t}-P_{\mathrm{Na}}\right) /\left(1-P_{\mathrm{Na}}\right)$ & 0.23 & 0.23 & 0.26 & 0.23 \\
Calculated fission product fuel swelling per unit burnup, ${ }^{\mathrm{c}} S_{f}$ & 0.021 & 0.017 & 0.017 & 0.017 \\
Decrease of gas-filled porosity per unit burnup, ${ }^{\mathrm{c}}\left(1-P_{t o t}\right) S_{f}$ & 0.015 & 0.011 & 0.012 & 0.012 \\
\hline
\end{tabular}

*Generally applicable for burnups $>2$ at.\%.

a Fissium (Fs) is a mixture of metals representing an equilibrium concentration of fission products after reprocessing.

${ }^{b}$ Fission product accumulation not included in this low-burnup estimate; estimated uncertainty is approximately \pm 0.02 .

'Uncertainty in these estimates is approximately $\pm 30 \%$.
Fraction of porosity filled with sodium
0.21
0.39
0.25
0.28

Figure 19. Estimates of sodium infiltration taken from Reference 20. The results indicate that for $75 \%$ smear density pins, about 20 to 40 percent of the porosity in the fuel will be filled with sodium. Based on the metallography and porosity estimates in Reference 20, more sodium infiltration can be expected for lower smear density pins.

The importance of sodium on the effective fuel thermal conductivity is illustrated in Figure $\mathbf{2 0}$ and Figure 21. Figure 20 shows thermal conductivity as a function temperature for different metallic fuel alloys, ${ }^{21}$ for zirconium and HT $-9,{ }^{21}$ and for sodium. ${ }^{22}$ Of all of the typical constituents of a fuel element, sodium clearly has the highest thermal conductivity in the temperature range of interest. A simple model for effective fuel thermal conductivity can be developed using the rule of mixtures, i.e.,

$$
\kappa_{\text {eff }}=\kappa_{\text {fuel }}(1-f)+\kappa_{\text {sodium }} f \cdot I
$$

where $\kappa_{\text {eff }}$ and $\kappa_{\text {fuel }}$ are the effective fuel thermal conductivity and the thermal conductivity of the fully-dense fuel alloy, respectively, $f$ is the pore volume fraction and $I$ is the fraction of porosity filled with bond sodium. Using this equation, assuming a temperature of $600^{\circ} \mathrm{C}$, and further assuming that the fuel is composed of pure uranium, Figure 21 shows the effective fuel thermal conductivity as a function of pore volume fraction and the amount of sodium infiltration. Not surprisingly, the plot shows the impact of sodium on effective thermal conductivity is most pronounced for cases where both the pore volume 
fraction and the amount of infiltration is high. The implication from this simple result is that the benefits of sodium are expected to be particularly important for low smear density designs where increased amounts of porosity and sodium infiltration are expected.

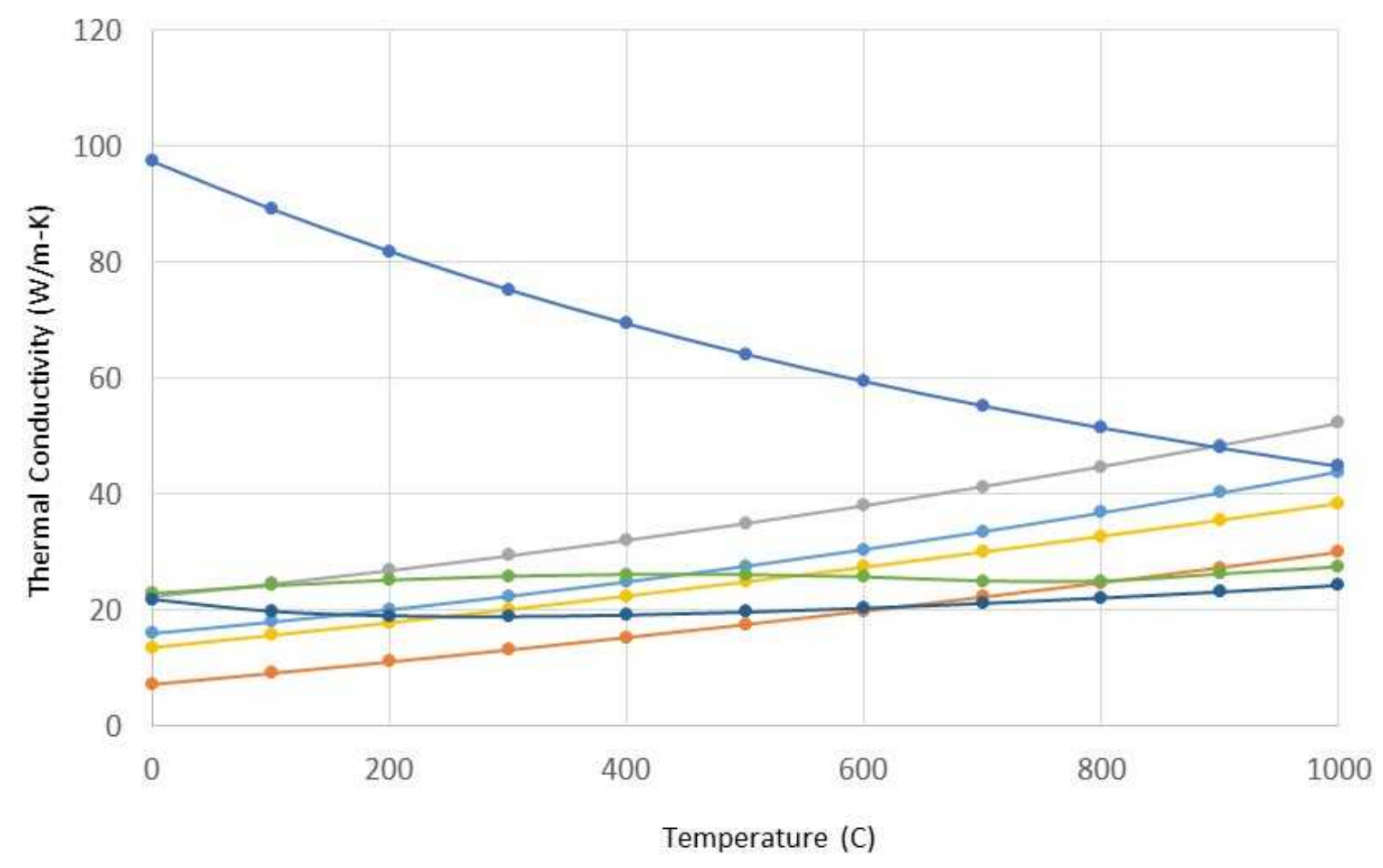

$$
\rightarrow \text { U-10Zr } \rightarrow \text { U-20Pu-10Zr } \rightarrow \text { U } \rightarrow \text { U-20Pu } \rightarrow \text { Sodium } \rightarrow-\mathrm{HT} 9 \rightarrow \mathrm{Zr}
$$

Figure 20. Estimates of thermal conductivity for different constituents that potentially comprise a metallic fuel pin ${ }^{21,22}$. Of all the constituents in a metallic fuel system, sodium has the highest thermal conductivity in the temperature range of interest. Also note that although the addition of zirconium to metallic fuel increases its solidus temperature, zirconium also reduces the thermal conductivity of uranium and uranium-plutonium alloys. 


$$
\begin{aligned}
& \kappa=\kappa_{\text {alloy }} f+\kappa_{\text {sodium }}(1-f) I \\
& f=\text { pore volume fraction } \\
& I=\text { fraction of porosity infiltrated }
\end{aligned}
$$

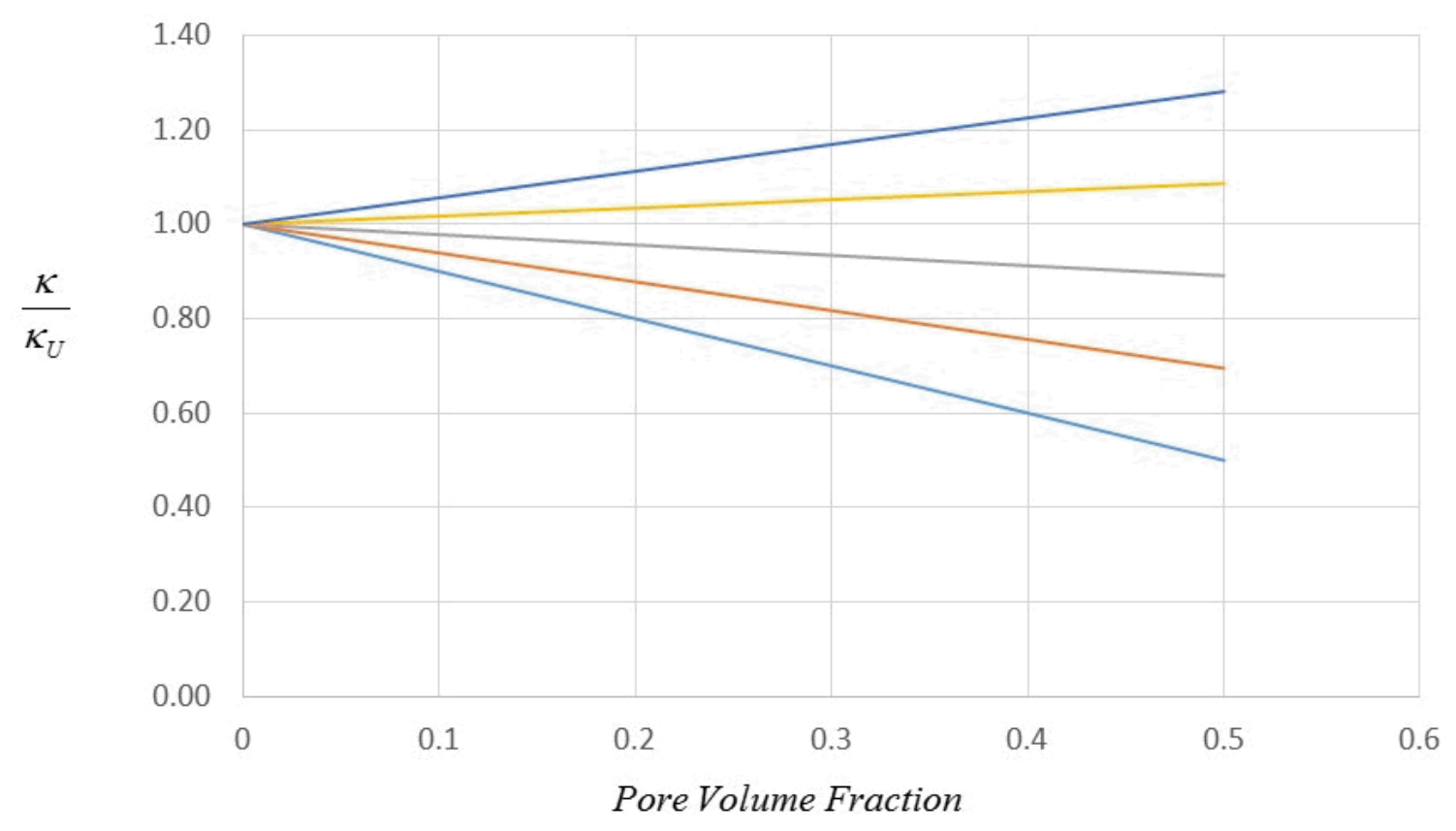

-Infiltration $=0.00-$ Infiltration $=0.25-$ Infiltration $=0.50 \quad$ Infiltration $=0.75 \longrightarrow$ Infiltration $=1.00$

Figure 21. Estimates of the effective thermal conductivity for uranium metal as a function of porosity and the fraction of porosity that has been infiltrated with sodium. Although the thermal conductivity model uses the (overly) simplistic rule of mixtures, a key trend can be nonetheless identified, namely that the effect of sodium on effective thermal conductivity is more pronounced at high values of fuel porosity and high values of sodium infiltration. Given that more sodium infiltration can be expected in fuels with high porosity, the results indicate that the advantage regarding the use of sodium bond is much more pronounced for high porosity (e.g., low smear density) fuel system designs.

The impact of sodium on fuel performance was estimated using the simple model for fuel thermal conductivity described above and by making the following assumptions:

1. A standard analytic expression was used to obtain peak fuel temperatures that assumed temperature-independent values for thermal conductivity. The effective fuel thermal conductivity was calculated assuming a temperature of $600^{\circ} \mathrm{C}$ while values for the cladding assumed a temperature $500^{\circ} \mathrm{C}$.

2. Cladding surface temperatures were assumed to be $550^{\circ} \mathrm{C}$. 
Solidus temperatures for different metallic fuel alloys were estimated from the phase diagrams and tables provided in Figure 22 and

Figure 23. These estimates are summarized in

\section{Table 1.}

4. In cases where a cladding liner is assumed, the thermal conductivity of the liner is assumed to be the same as the cladding itself.

5. Fuel porosity is assumed to be given by the expression $f=(1-S D)$, where $S D$ is the assumed smear density for the fuel design. This equation essentially assumes no axial swelling of the fuel and does not account for the accumulation of solid fission products.

6. For fuel systems with a smear density of 75 percent, 30 percent of the porosity is assumed to be occupied by sodium, which is approximately consistent with the measurements performed in Reference 20. For fuel systems with smear densities of about 60 percent, the bond sodium is somewhat arbitrarily assumed to infiltrate 50 percent of the available porosity.

7. EBR-2 cladding diameters and thicknesses are assumed.

8. In cases where a liner is assumed, smear density is defined as the ratio of the fuel area to the area within the inside of the liner.

9. The analyses do not account for the effects of constituent migration and the associated spatial variations in fuel thermal conductivity, power density, and solidus temperature.

10. In cases where allowable powers are estimated, fuel centerline temperatures and not fuel/cladding eutectic temperatures are assumed to be limiting.

Of course, given the number of approximations used, the precise values that come out of the calculations are less important than the trends that are identified from the analyses.

Table 2 provides example fuel element designs that will be used to explore the effects of sodium on fuel centerline temperatures and margins to fuel melting. Three basic categories of fuel designs are considered: (1) the standard U-10Zr, 75\% smear density, sodium-bonded design; (2) U-10Zr and U-20Pu$10 \mathrm{Zr}$ alloys, $75 \%$ smear density, and annular fuel without bond sodium that would be candidates for the Versatile Test Reactor; and (3) low smear density, high burnup designs that would be used for enhanced actinide utilization. Note that in the high burnup designs, either pure uranium or a U-20Pu alloy was chosen to offset the reduction in heavy metal loading associated with a low smear density fuel design.

Figure 24 plots margin to centerline melting based on some of the fuel designs listed in Table 2. The plots show that the cases with low smear density, using either pure uranium or an alloy of U-20Pu, and the incorporation of bond sodium have as much margin to melting as corresponding cases with sodiumfree annular fuel designs having either U-10Zr or U-20Pu-10Zr alloys and with smear densities of 75 percent. The results indicate that the presence of sodium in the low smear density cases and the better thermal conductivity of the pure uranium or the U-20Pu alloy is enough to offset the corresponding reduction in the solidus temperature. 


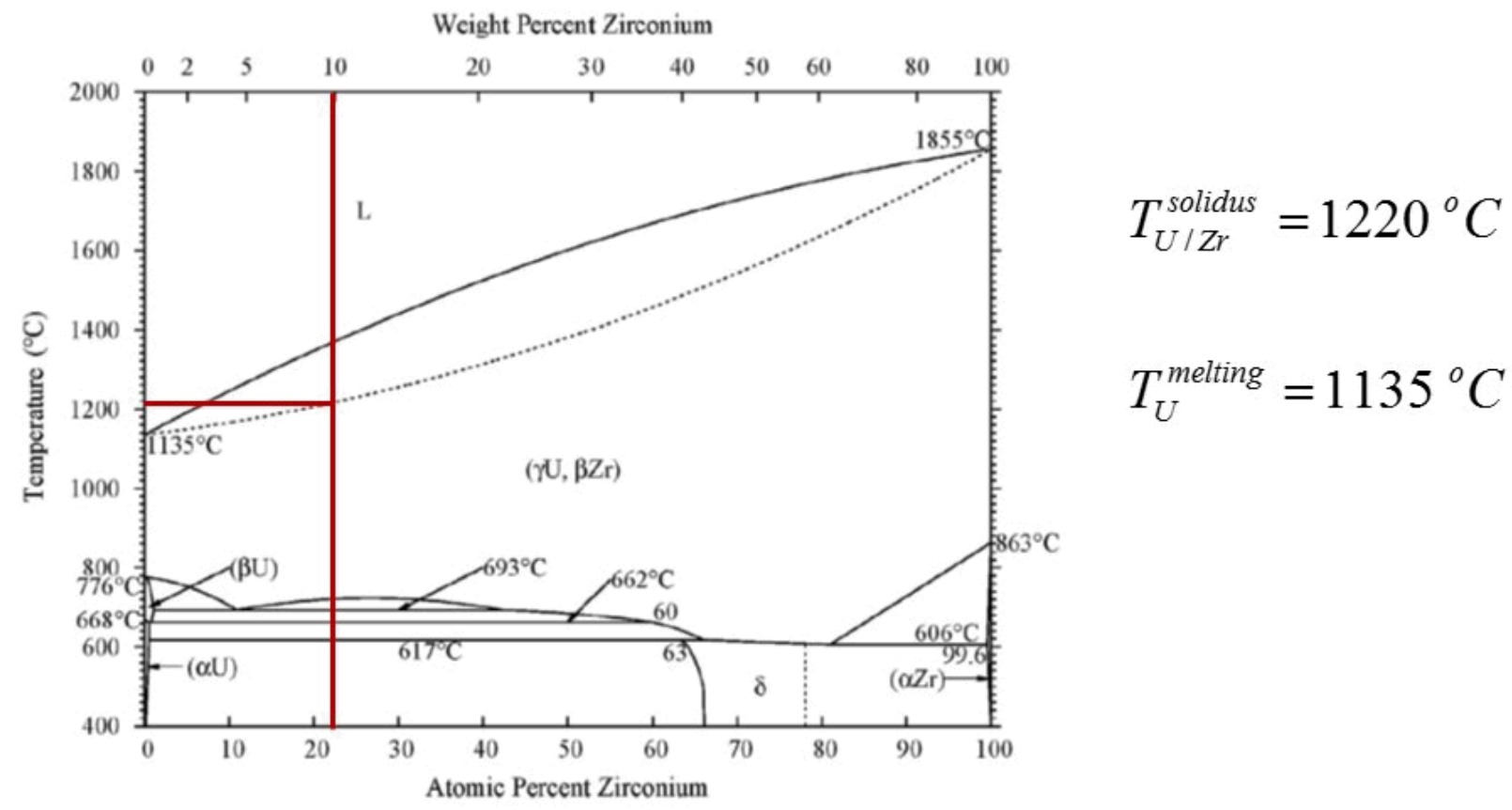

(a)

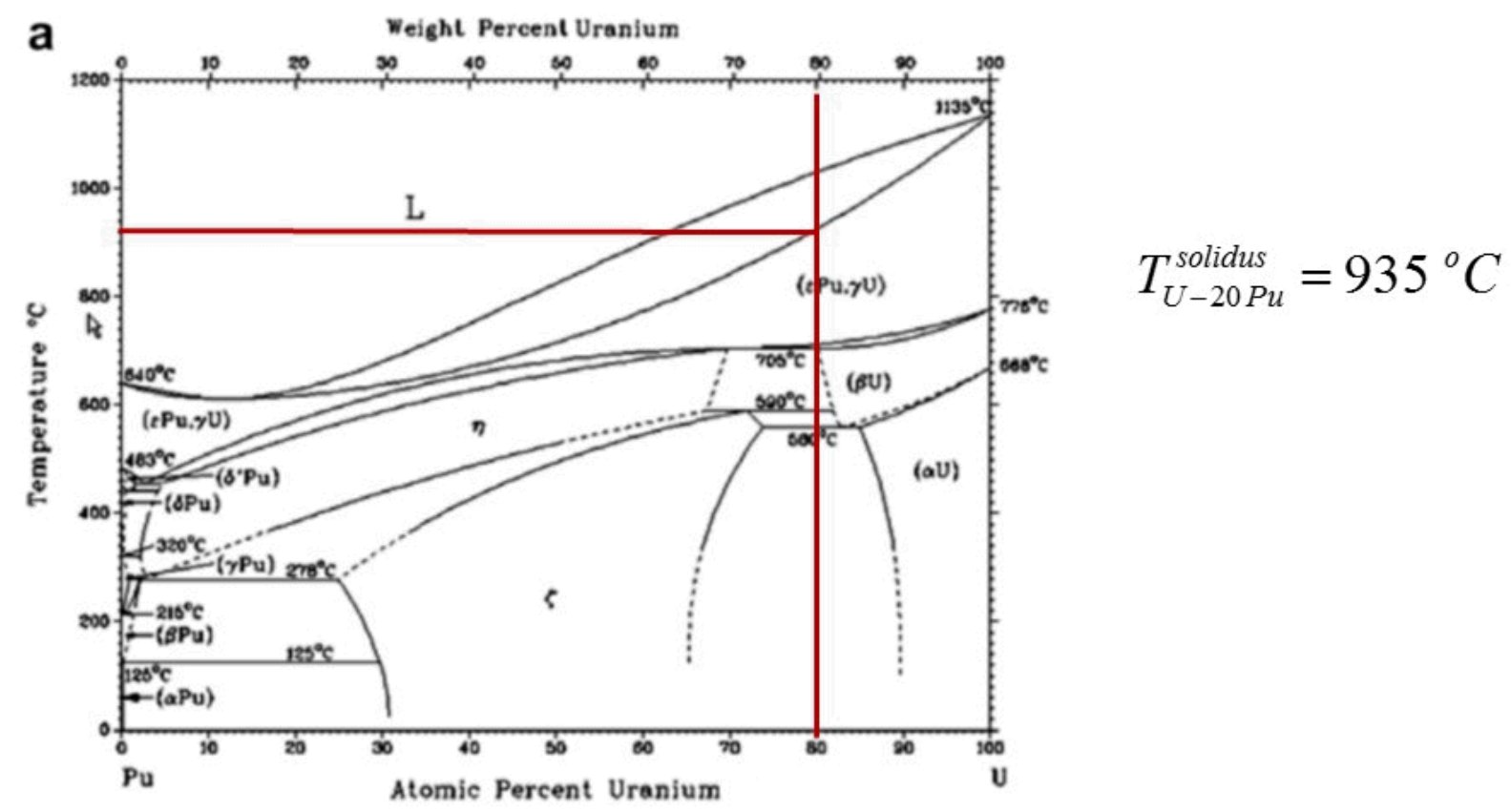

(b)

Figure 22. Estimates of solidi temperatures for uranium-zirconium ${ }^{26}$ and uranium-plutonium alloys. ${ }^{27}$ 
TABLE XXIV. Melting Pounts of Metallac Fuels

\begin{tabular}{|c|c|c|}
\hline \multirow[b]{2}{*}{ Fuel Alloy, we \% } & \multicolumn{2}{|c|}{ Melting Point, 'F } \\
\hline & Solidus: & Liquisdu* \\
\hline \multirow{10}{*}{ 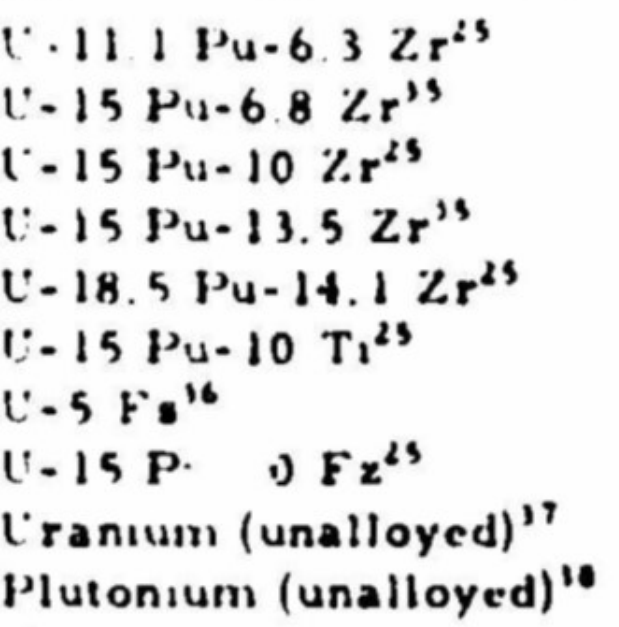 } & -2050 & -2140 \\
\hline & $2020 \div 20$ & $2260 \div+0$ \\
\hline & -2110 & -2280 \\
\hline & $2180 \cdot 20$ & $2600: 40$ \\
\hline & $21+0$ & -2350 \\
\hline & -2190 & $=2+40$ \\
\hline & $1836: 10$ & $1978=10$ \\
\hline & -1590 & -1830 \\
\hline & $2070: 2$ & $2070: ?$ \\
\hline & $1185: 5$ & $1185: 5$ \\
\hline \multicolumn{3}{|c|}{$T_{U-18.5 P u-14.1 \mathrm{Zr}}^{\text {solidus }}=1170^{\circ} \mathrm{C}$} \\
\hline \multicolumn{3}{|c|}{$T_{U-15 \mathrm{Pu}-10 \mathrm{Zr}}^{\text {solidus }}=1155^{\circ} \mathrm{C}$} \\
\hline$T_{U-20 F}^{\text {solidu }}$ & $1150^{\circ} \mathrm{C}$ & \\
\hline
\end{tabular}

Figure 23. Estimates of solidus temperatures for U-Pu-Zr alloys from Reference 25.

Table 1. Estimates of Solidus or Melting Point for a Variety of Potential Metal Fuels.

\begin{tabular}{|c|c|}
\hline Alloy & $\begin{array}{c}\text { Solidus or Melting Point } \\
\left({ }^{\circ} \mathrm{C}\right)\end{array}$ \\
\hline $\mathrm{U}-10 \mathrm{Zr}$ & 1220 \\
\hline $\mathrm{U}-20 \mathrm{Pu}-10 \mathrm{Zr}$ & 1150 \\
\hline $\mathrm{U}$ & 1135 \\
\hline $\mathrm{U}-20 \mathrm{Pu}$ & 935 \\
\hline
\end{tabular}


Table 2. Examples of Different Fuel Element Designs to Illustrate the Effects of Bond Sodium.

\begin{tabular}{|c|c|c|c|c|c|c|c|c|c|c|}
\hline Category & Alloy & $\begin{array}{l}\text { Na } \\
\text { Bond }\end{array}$ & $\begin{array}{c}\text { Pin } \\
\text { Diameter } \\
\text { (in.) }\end{array}$ & $\begin{array}{l}\text { Cladding } \\
\text { Thickness } \\
\text { (in.) }\end{array}$ & $\begin{array}{c}\text { Liner } \\
\text { Thickness } \\
\text { (in.) }\end{array}$ & $\begin{array}{l}\text { Smear } \\
\text { Density }\end{array}$ & $\begin{array}{c}\text { Wire } \\
\text { Wrap } \\
\text { Diameter } \\
\text { (in.) }\end{array}$ & $\begin{array}{c}\text { Linear } \\
\text { Power } \\
(\mathrm{kW} / \mathrm{m})\end{array}$ & $\begin{array}{c}\text { Fraction } \\
\text { of Fissile } \\
\text { HM }\end{array}$ & $\begin{array}{l}\text { Volume } \\
\text { Fraction } \\
\text { of Fissile }\end{array}$ \\
\hline Standard & U-10Zr & $\begin{array}{l}30 \% \\
\text { Filled }\end{array}$ & 0.230 & 0.018 & 0.000 & 0.75 & 0.042 & 90 & 0.200 & 0.054 \\
\hline \multirow{3}{*}{$\begin{array}{c}\text { 2nd } \\
\text { Generation } \\
\text { VTR } \\
\text { Designs }\end{array}$} & U-10Zr & No & 0.230 & 0.018 & 0.000 & 0.75 & 0.042 & 90 & 0.200 & 0.054 \\
\hline & $\begin{array}{c}\mathrm{U}-20 \mathrm{Pu}- \\
10 \mathrm{Zr}\end{array}$ & No & 0.230 & 0.018 & 0.000 & 0.75 & 0.042 & 90 & 0.344 & 0.092 \\
\hline & $\mathrm{U}$ & $\begin{array}{c}50 \% \\
\text { Filled } \\
\end{array}$ & 0.230 & 0.018 & 0.003 & 0.62 & 0.042 & 90 & 0.200 & 0.054 \\
\hline \multirow{4}{*}{$\begin{array}{l}\text { Designs } \\
\text { for } \\
\text { Enhanced } \\
\text { Actinide } \\
\text { Utilization/ } \\
\text { High } \\
\text { Burnup } \\
\text { Designs }\end{array}$} & $\mathrm{U}$ & No & 0.230 & 0.018 & 0.003 & 0.62 & 0.042 & 90 & 0.200 & 0.054 \\
\hline & $\mathrm{U}-20 \mathrm{Pu}$ & $\begin{array}{l}50 \% \\
\text { Filled } \\
\end{array}$ & 0.230 & 0.018 & 0.003 & 0.62 & 0.042 & 90 & 0.330 & 0.089 \\
\hline & $\mathrm{U}-20 \mathrm{Pu}$ & No & 0.230 & 0.018 & 0.003 & 0.62 & 0.042 & 90 & 0.330 & 0.089 \\
\hline & $\mathrm{U}-10 \mathrm{Zr}$ & $\begin{array}{l}30 \% \\
\text { Filled }\end{array}$ & 0.230 & 0.018 & 0.000 & 0.75 & 0.042 & 90 & 0.200 & 0.054 \\
\hline
\end{tabular}

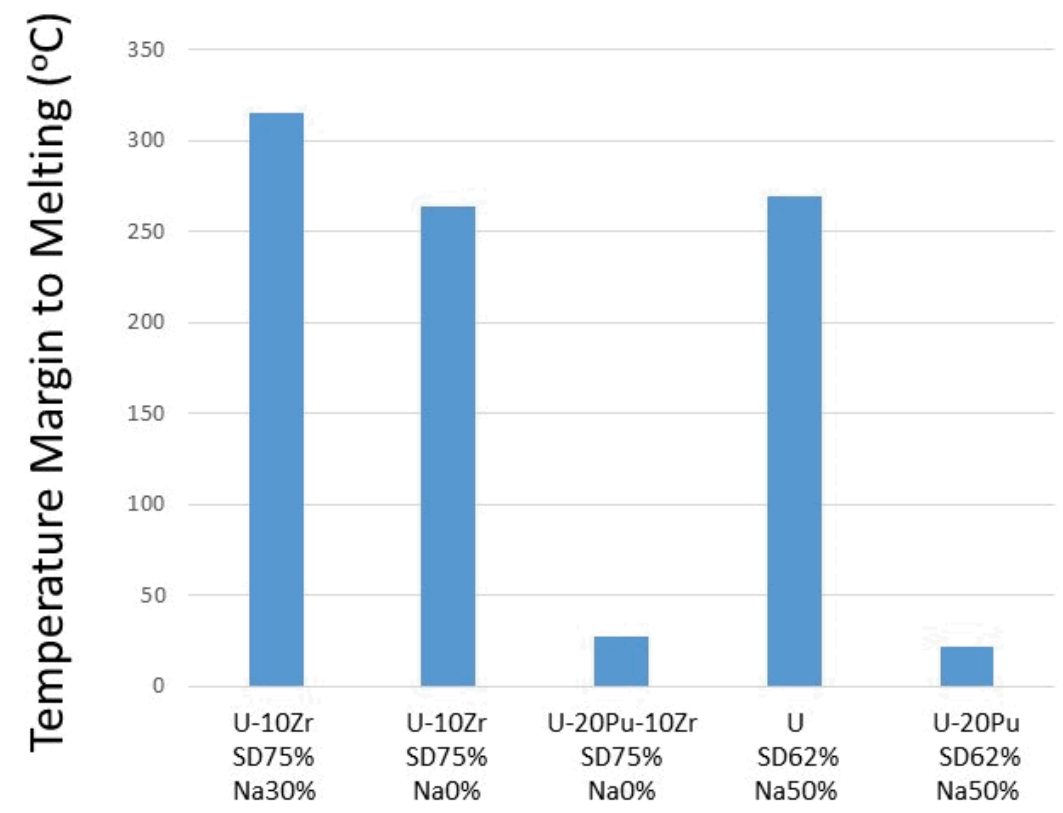

Figure 24. Fuel systems designed to achieved high burnup (low smear density, liner, zirconium removed from the fuel alloy, sodium bond, (see Table 2) have about the same margin to centerline melting as annular fuel designs with 75\% smear density, no sodium bond, and the use of standard metal fuel alloys with $10 w t \%$ Zr. For these cases, the addition of the bond sodium in the high burnup designs is enough to offset reduced smear density and the low melting points of the uranium and uranium-plutonium alloys. $A$ key assumption in these estimates, however, is that the low smear density in the high burnup designs will enable 50 percent of the porosity to be filled with sodium. See also Table 2 for assumptions made in the analyses. 
The effect bond sodium on predicted power-to-centerline melting is studied for fuel designs with $75 \%$ smear density U-10Zr, $62 \%$ smear density pure uranium, and $62 \%$ smear density U-20Pu; results of these calculations are shown in Figure 25. The impact of sodium bond is greater in the low smear density cases because the effect of sodium on thermal conductivity is greater with higher porosity and higher amounts of infiltration. The impact on power is greater for $\mathrm{U}-20 \mathrm{Pu}$ than for pure uranium (on a percentage basis) because $\mathrm{U}-20 \mathrm{Pu}$ has lower thermal conductivity than uranium so the addition of sodium has a greater impact on the net thermal conductivity of $\mathrm{U}-20 \mathrm{Pu}$. These results are also summarized in

Table 3 where the substantial benefit of sodium for the low smear density cases is quantified.

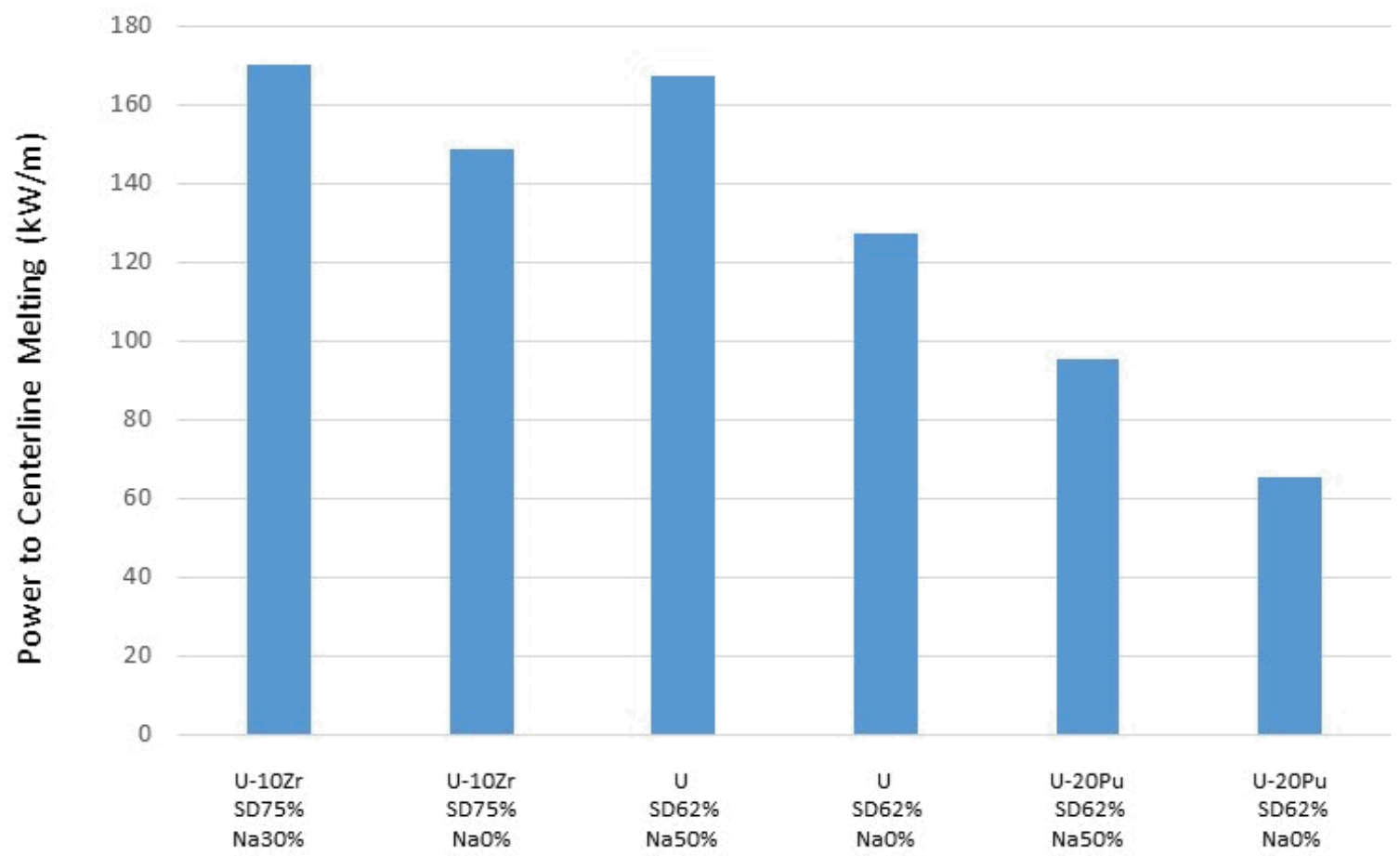

Figure 25. The impact of sodium bond on power-to-centerline melting is greater in the low smear density cases because the effect of sodium on thermal conductivity is greater with higher porosity and higher amounts of infiltration. The impact on power is greater for U-20Pu than for pure uranium (on a percentage basis) because U-20Pu has lower thermal conductivity than uranium so the addition of sodium has a greater impact on the net thermal conductivity of $U-20 P u$.

Table 3. Increase in Power-to-Melt Associated with the Presence of Bond Sodium.

\begin{tabular}{|c|c|c|}
\hline Alloy & $\begin{array}{c}\text { Smear Density } \\
(\mathbf{\%})\end{array}$ & $\begin{array}{c}\text { Increase in Power Associated with Na Bond } \\
\text { (\%) }\end{array}$ \\
\hline $\mathrm{U}-10 \mathrm{Zr}$ & 75 & 14 \\
\hline $\mathrm{U}$ & 62 & 31 \\
\hline $\mathrm{U}-20 \mathrm{Pu}$ & 62 & 46 \\
\hline
\end{tabular}




\section{PRELIMINARY FUTURE TEST PLANS}

For a once-through fuel system, the elimination of bond sodium is preferred so that spent fuel can be sent directly to a repository without treatment. In this case, an annular fuel geometry with either a mechanical bond or with a narrow helium-filled gap between the fuel and cladding provides the best heat transfer from the fuel into the coolant. The focus of development will be on designs appropriate for the second generation, sodium-free fuel system associated with the Versatile Test Reactor. For this application, burnup requirements are expected to be on the order of 10 at.\%, so designs that use well-studied fuel alloys of either U-10Zr or U-20Pu-10Zr combined with a smear density of 75 percent are expected to be sufficient.

For a design that involves recycling of the fuel, high burnup designs provide substantial economic benefits, which in turn implies low smear densities to accommodate the accumulation of fission products. In this case, the presence of bond sodium provides significant benefit in terms of heat transfer and results in little additional cost to recycle the fuel. Unfortunately, the fabrication of annular fuel in a hot cell is judged to be difficult, while slotted fuel designs can likely be manufactured by casting (see Figure $\mathbf{2 6}$ for a schematic). ${ }^{23}$ Concerns associated with slotted fuel designs include distortion of the fuel pin because of the non-uniform pressure exerted by the fuel onto the cladding and the potential for increased axial growth when compared to an annular design. However, once the fuel has swelled into the available void space (typically by 1-2 atom\% burnup), the effect of the initial fuel geometry should be minimal.

Figure 27 provides examples of different slotted fuel designs. From a fuel performance perspective, more symmetric slot arrangements and deeper but narrower slots are likely to be preferred to both minimize cladding distortion and to limit fuel axial growth. The use of fuel performance models that have been benchmarked against Russian data on slotted fuel would be helpful in assessing concerns regarding cladding deformation and axial extension of the fuel. These designs are expected to use fuels with a high heavy metal density such as pure uranium or uranium-plutonium alloys to compensate for low smear density and a liner to prevent fuel/cladding chemical interactions. However, alloys that increase the fuel solidus temperature would allow for larger diameter pins and could potentially provide an alternative means for increasing loading density within a fuel assembly.

An alternative to both annular and slotted fuel designs would be to fabricate porous metallic fuel.

Figure 28 shows an example of a directional solidification process that allows for elongated pores within the casting. ${ }^{24}$ If sodium bond was used in conjunction with fuel with elongated porosity, one potential advantage is that bond sodium could potentially be infiltrated into the fuel during fabrication and thereby reduce the uncertainty regarding the amount of sodium in the fuel during the course of irradiation. For the present time, however, annular fuel is the default geometry for once-through fuel systems and slotted designs are assumed to be more appropriate for the recycled fuel designs.

Given that annular U-10Zr and U-20Pu-10Zr can be fabricated at the INL Materials and Fuels Complex (MFC) with relatively short notice, once-through, sodium-free annular fuel designs based on these alloys will likely be the next set of rodlets to be tested. Table 4 provides an example test matrix, although a substantial amount of work is required before this test matrix is finalized. A similar notional test matrix has been developed for fuel systems that require recycling (see Table 5). A key near-term effort in this regard will be the development of zirconium and/or vanadium liners for these designs. 


\section{Once-Through \\ - No sodium bond \\ - Extrusion \\ - Annularfuel \\ - Mechanical or helium bond}

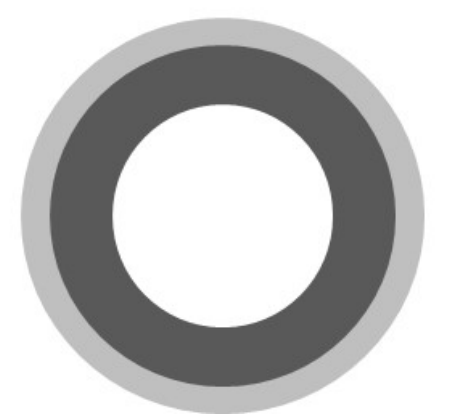

(a)

\section{Recycle}

- Sodium bond

- Injection cast

- Slotted design to accommodate fuel fab

- Sodium bond

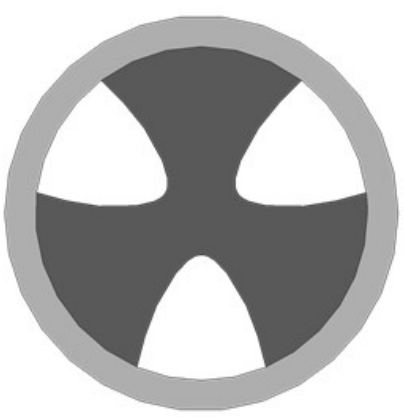

(b)

Figure 26. Example fuel designs for (a) a once-through fuel system; and (b) a design when fuel recycling is anticipated.
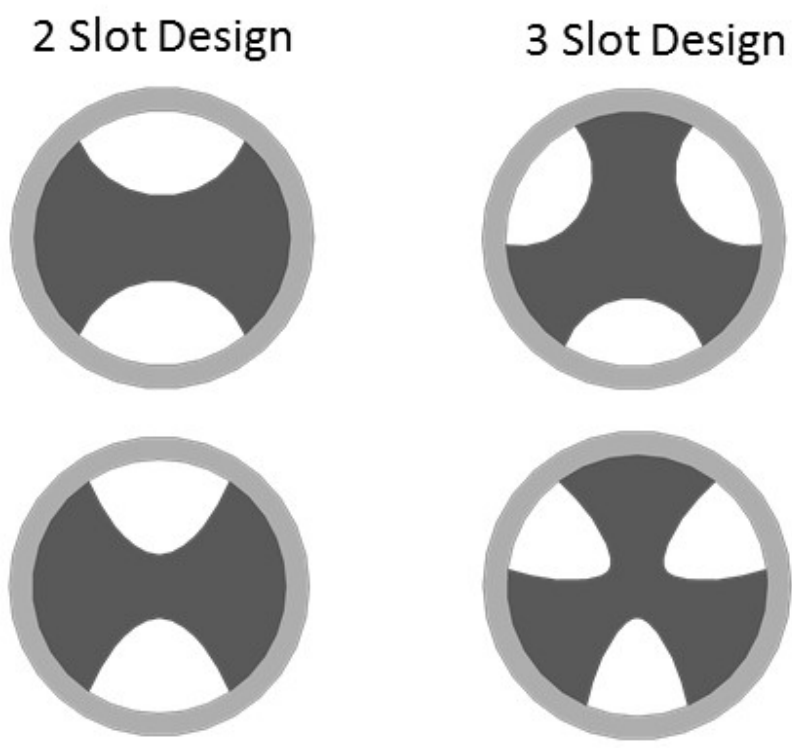

4 Slot Design
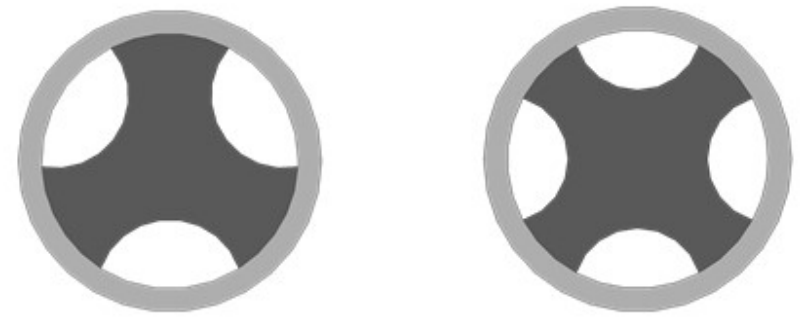

\section{Circular}

Slots
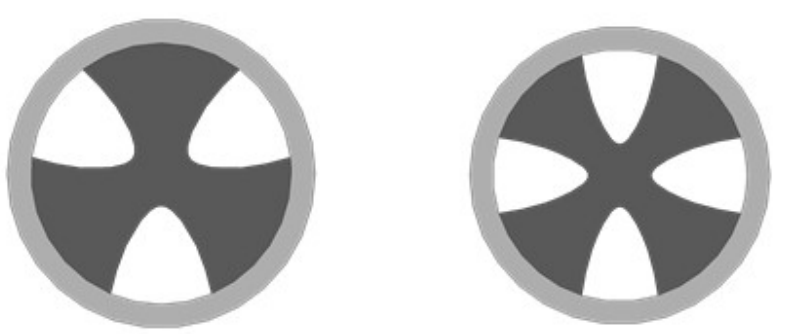

Parabolic

Slots

Figure 27. Examples of slotted fuel designs with about 60 percent smear density. 


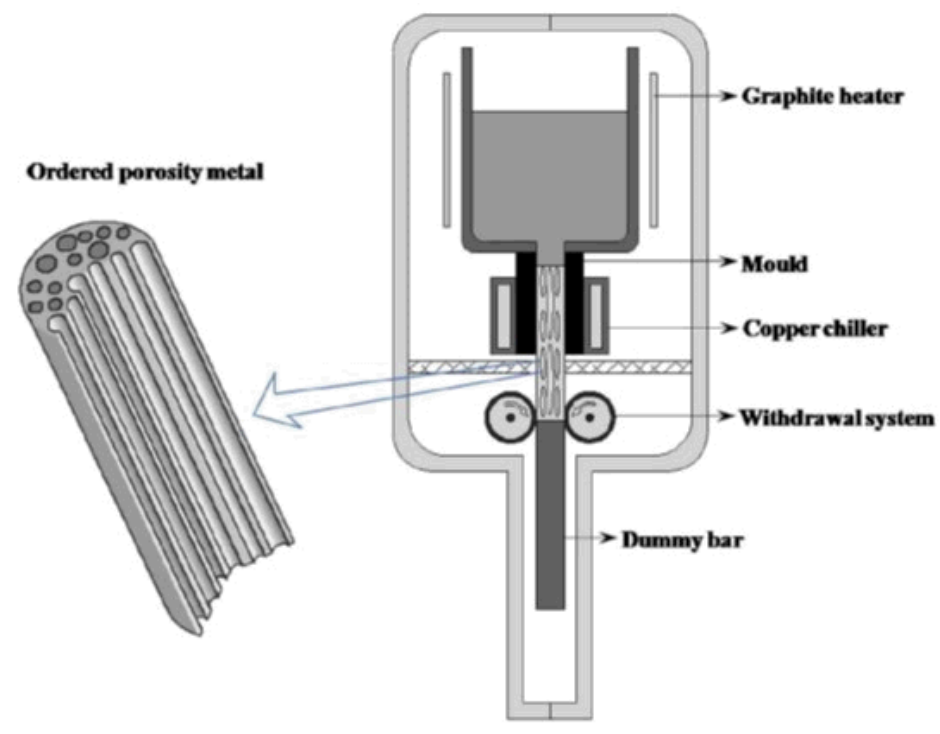

(a)

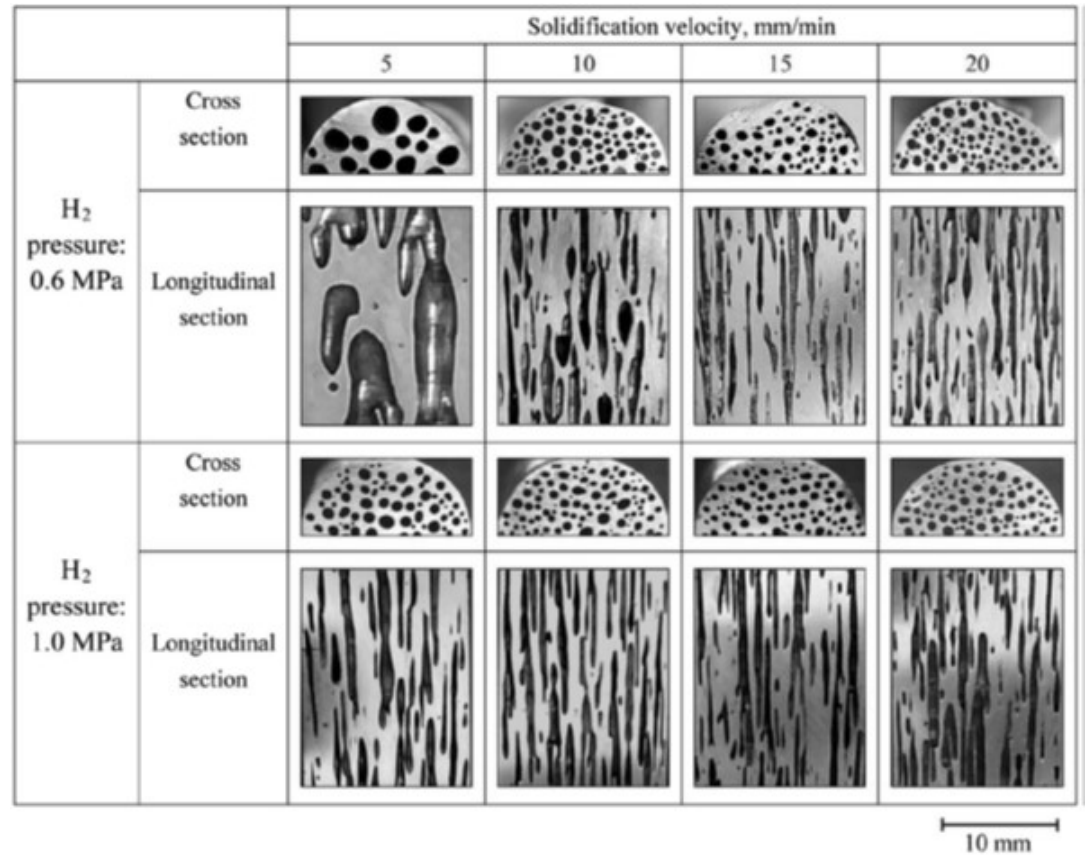

(b)

Figure 28. (a) Schematic of directional solidification of a gas-saturated melt and the elongated porosity that can result; and (b) Metallography of porosity in copper fabricated under different conditions (Figures were taken from Reference 24). An alternative to both annular and slotted fuel designs would be porous fuel. 
Table 4. Test Matrix for Once-Through Fuel Element Designs.

\begin{tabular}{|c|c|c|c|c|c|c|}
\hline Alloy & $\begin{array}{c}\text { Na } \\
\text { Bond }\end{array}$ & $\begin{array}{c}\text { Fuel } \\
\text { Shape }\end{array}$ & Liner & $\begin{array}{c}\text { Smear } \\
\text { Density }\end{array}$ & $\begin{array}{c}\text { Targeted } \\
\text { Burnup } \\
\text { atom\%) }\end{array}$ & $\begin{array}{c}\text { Follow-on } \\
\text { Studies }\end{array}$ \\
\hline $\mathrm{U}-20 \mathrm{Pu}-10 \mathrm{Zr}$ & No & Annular & No & 0.75 & 5 & PIE \\
\hline $\mathrm{U}-20 \mathrm{Pu}-10 \mathrm{Zr}$ & No & Annular & No & 0.75 & 10 & PIE \\
\hline $\mathrm{U}-20 \mathrm{Pu}-10 \mathrm{Zr}$ & No & Annular & No & 0.75 & 15 & PIE \\
\hline $\mathrm{U}-20 \mathrm{Pu}-10 \mathrm{Zr}$ & No & Annular & No & 0.75 & 5 & TREAT \\
\hline $\mathrm{U}-20 \mathrm{Pu}-10 \mathrm{Zr}$ & No & Annular & No & 0.75 & 10 & TREAT \\
\hline $\mathrm{U}-20 \mathrm{Pu}-10 \mathrm{Zr}$ & No & Annular & No & 0.75 & 15 & TREAT \\
\hline $\mathrm{U}-10 \mathrm{Zr}$ & No & Annular & No & 0.75 & 5 & PIE \\
\hline $\mathrm{U}-10 \mathrm{Zr}$ & No & Annular & No & 0.75 & 10 & PIE \\
\hline $\mathrm{U}-10 \mathrm{Zr}$ & No & Annular & No & 0.75 & 15 & PIE \\
\hline $\mathrm{U}-10 \mathrm{Zr}$ & No & Annular & No & 0.75 & 5 & TREAT \\
\hline $\mathrm{U}-10 \mathrm{Zr}$ & No & Annular & No & 0.75 & 10 & TREAT \\
\hline $\mathrm{U}-10 \mathrm{Zr}$ & No & Annular & No & 0.75 & 15 & TREAT \\
\hline
\end{tabular}

Table 5. Test Matrix for Recycling Fuel Element Designs.

\begin{tabular}{|c|c|c|c|c|c|c|}
\hline Alloy & $\begin{array}{c}\text { Na } \\
\text { Bond }\end{array}$ & $\begin{array}{c}\text { Fuel } \\
\text { Shape }\end{array}$ & Liner & $\begin{array}{c}\text { Smear } \\
\text { Density }\end{array}$ & $\begin{array}{c}\text { Targeted } \\
\text { Burnup } \\
\text { (atom\%) }\end{array}$ & $\begin{array}{c}\text { Follow-on } \\
\text { Studies }\end{array}$ \\
\hline $\mathrm{U}$ & Yes & Slotted & Vanadium & 0.62 & 10 & PIE \\
\hline $\mathrm{U}$ & Yes & Slotted & Vanadium & 0.62 & 20 & PIE \\
\hline $\mathrm{U}$ & Yes & Slotted & Vanadium & 0.62 & 30 & PIE \\
\hline $\mathrm{U}$ & Yes & Slotted & Zirconium & 0.62 & 10 & PIE \\
\hline $\mathrm{U}$ & Yes & Slotted & Zirconium & 0.62 & 20 & PIE \\
\hline $\mathrm{U}$ & Yes & Slotted & Zirconium & 0.62 & 30 & PIE \\
\hline $\mathrm{U}-20 \mathrm{Pu}$ & Yes & Slotted & Vanadium & 0.62 & 10 & PIE \\
\hline $\mathrm{U}-20 \mathrm{Pu}$ & Yes & Slotted & Vanadium & 0.62 & 20 & PIE \\
\hline $\mathrm{U}-20 \mathrm{Pu}$ & Yes & Slotted & Vanadium & 0.62 & 30 & PIE \\
\hline $\mathrm{U}-20 \mathrm{Pu}$ & Yes & Slotted & Zirconium & 0.62 & 10 & PIE \\
\hline $\mathrm{U}-20 \mathrm{Pu}$ & Yes & Slotted & Zirconium & 0.62 & 20 & PIE \\
\hline $\mathrm{U}-20 \mathrm{Pu}$ & Yes & Slotted & Zirconium & 0.62 & 30 & PIE \\
\hline
\end{tabular}




\section{REFERENCES}

1. Y. S. Kim, G. L. Hoffman, and A. M. Yacout, "Migration of Minor Actinides and Lanthanides in Fast Reactor Metallic Fuel,” Journal of Nuclear Materials, 392 (2009).

2. L.R. Blake, "Achieving High Burnup in Fast Reactors," Reactor Science and Technology 14 (1961)

3. R.S. Barnes, "A Theory of Swelling and Gas Release for Reactor Materials," Journal of Nuclear Materials 11 (1964)

4. R. D. Mariani, D. L. Porter, T. P. O'Holleran, S. L. Hayes, and J. R. Kennedy, "Lanthanides in Metallic Nuclear Fuels: Their Behavior and Methods for Their Control," Journal of Nuclear Materials 419 (2011).

5. D. D. Keiser and J. I. Cole, “An Evaluation of Potential Liner Materials for Eliminating FCCI in Irradiated Metallic Nuclear Fuel Elements,” INL/CON-07-12189 (2007).

6. W. N. Beck, R. J. Fousek, and J. H. Kittel, "The Irradiation Behavior of High-Burnup UraniumPlutonium Alloy Prototype Fuel Elements,” ANL-7388 (1968).

7. B. Kryger, "Contribution a L'etude du Degagement des Gaz de Fission danes les Combustibles Nucleaires Metalliques," Rapport CEA-R-3888, October 1969).

8. M. Cappiello, R. Hobbins, K. Penny, L. Walters, "Independent Review of AFC 2A, 2B, and 2E ATR Irradiation Tests,” INL/EXT-14-31445 (2014).

9. L. Capriotti and J. M. Harp, unpublished work (2017).

10. D.J. Senor, "Recommendations for Tritium Science and Technology Research and Development in Support of the Tritium Readiness Campaign TTP-7-084," PNNL-22873 (2013)

11. B.P. Collin, “AGR-3/4 Irradiation Test Final As-Run Report,” INL/EXT-15-35550 (2015)

12. J. M. Harp and H. J. M. Chichester, "Baseline Postirradiation Examination of the AFC-2D, AFC-2E, AFC-3A and AFC-3B Experiments," INL/LTD-15-36358 (2015).

13. J. I. Cole, T. P. O’Holleran, D. D. Keiser, and J. R. Kennedy, "FY2010 FCCI Studies Draft Report," INL/LTD-10-20611 (2010).

14. J. M. Harp, unpublished work (2017).

15. Yu. M. Golovchenko, "Some Results of Developments and Investigations of Fuel Pins with Metal Fuel for Heterogeneous Core of Fast Reactors of the BN-Type," Energy Procedia 7 (2011)

16. Yu. M. Golovchenko, "Radiation and Thermal Effects in Experimental High Dense Metal Fuel Elements for Advanced LMFR,” Energy Research Journal 4 (2013).

17. Yu. M. Golovchenko, "Oxide-Metal Core is Possible Transition to the Metal Fuel Core for Fast Reactors of the BN-Type,” International Journal of Energy and Power Engineering 2 (2013).

18. A. Kumar, "Development, Fabrication, and Characterization of Fuels for Indian Fast Reactor Program," International Conference on Fast Reactors, Paris (2013).

19. G. L. Hofman, W. N. Beck, R. V. Strain, G. O. Hayner, and C. M. Walter, "Irradiation Behavior of Unencapsulated EBR-II Mark-II Driver Fuel to a Maximum Burnup of 6 at\%,” ANL-8119 (1976).

20. T. H. Bauer and J. W. Holland," In-Pile Measurement of the Thermal Conductivity of Irradiated Metallic Fuel," Nuclear Technology (1992).

21. J. D. Hales et al., "BISON Theory Manual," INL/EXT-13-29930 (2016). 
22. J. K. Fink and L. Leibowitz, "Thermodynamic and Transport Properties of Sodium Liquid and Vapor," ANL/RE-95/2 (1995).

23. Randy Fielding, personal communication, (2017).

24. Y. Lu, Z. Wen, Q. Jin, Y. Jiang, “A Thermodynamic Model for Simultaneous Growth of Gas and Solid Phases from Gas Saturated Melt," International Journal of Heat and Mass Transfer 91 (2015).

25. C. M. Walter, G. H. Golden, and N. J. Olson, "U-Pu-Zr Metal Alloy: A Potential Fuel for LMFBRs," ANL-76-28 (1975).

26. S. Ahn, S. Irukuvarghula, S. M. McDeavitt, "Thermophysical Investigations of the UraniumZirconium Alloy System," Journal of Alloys and Compounds 611 (2014).

27. S. S. Hecker and M. Stan, "Properties of Plutonium and its Alloys for Use as Fast Reactor Fuels," Journal of Nuclear Materials 383 (2008). 